\title{
Numerical Investigations of Unsteady Flow in a Centrifugal Pump with a Vaned Diffuser
}

\author{
Olivier Petit and Håkan Nilsson \\ Department of Fluid Dynamics, Chalmers University of Technology, Hörsalsvägen 7A, 41296 Gothenbourg, Sweden \\ Correspondence should be addressed to Olivier Petit; olivieralainp@gmail.com
}

Received 8 February 2013; Revised 16 May 2013; Accepted 30 May 2013

Academic Editor: J.-C. Han

Copyright (C) 2013 O. Petit and H. Nilsson. This is an open access article distributed under the Creative Commons Attribution License, which permits unrestricted use, distribution, and reproduction in any medium, provided the original work is properly cited.

Computational fluid dynamics (CFD) analyses were made to study the unsteady three-dimensional turbulence in the ERCOFTAC centrifugal pump test case. The simulations were carried out using the OpenFOAM Open Source CFD software. The test case consists of an unshrouded centrifugal impeller with seven blades and a radial vaned diffuser with 12 vanes. A large number of measurements are available in the radial gap between the impeller and the diffuse, making this case ideal for validating numerical methods. Results of steady and unsteady calculations of the flow in the pump are compared with the experimental ones, and four different turbulent models are analyzed. The steady simulation uses the frozen rotor concept, while the unsteady simulation uses a fully resolved sliding grid approach. The comparisons show that the unsteady numerical results accurately predict the unsteadiness of the flow, demonstrating the validity and applicability of that methodology for unsteady incompressible turbomachinery flow computations. The steady approach is less accurate, with an unphysical advection of the impeller wakes, but accurate enough for a crude approximation. The different turbulence models predict the flow at the same level of accuracy, with slightly different results.

\section{Introduction}

In centrifugal pumps, the relative motion between the rotor and stator and the small radial gap between the impeller blades and diffuser vanes result in a highly unsteady flow. This unsteadiness creates high pressure fluctuations, which are in turn responsible for unsteady dynamic forces that create vibrations and can cause damage. A large amount of detailed experimental investigations have therefore been dedicated to understanding the flow in centrifugal pumps. Among those, Dring et al. [1] showed that the two major sources of unsteadiness are potential and blade/wake interactions. In centrifugal turbomachines, the effects of these sources of unsteadiness become comparable [2]. On the basis of the studies mentioned above, Ubaldi et al. [3] built a simplified model of a centrifugal pump with a rotatable vaned diffuser to study rotor-stator interaction. They then investigated the upstream effect of the vaned diffuser on the impeller outflow in the radial gap of the model, as well as the flow in the impeller [4-6].
The experimental work contributes to an understanding of the flow complexity owing to rotor-stator interaction in the centrifugal pump. However, the knowledge is limited to the number of measurement points. For an extensive and detailed analysis of the flow, many different probes must be positioned in the geometry, although the complete flow field is not monitored. Computational fluid dynamics (CFD) techniques have been shown in the recent decades to be a useful complement to experiments. CFD calculations can provide more extensive results in the whole domain, giving a better overall understanding of the flow in the whole turbomachine. In recent years, improved computational algorithms and hardware development have shown convincing evidence that CFD calculations are reliable tools that can be used to analyze the unsteadiness of the flow [7]. However, the methods and software used to make the CFD calculations must be validated by experiments. To achieve this, the European Research Community on Flow Turbulence and Combustion (ERCOFTAC), together with Ubaldi et al. [3], adopted the centrifugal test rig as a test case for joint experimental and 


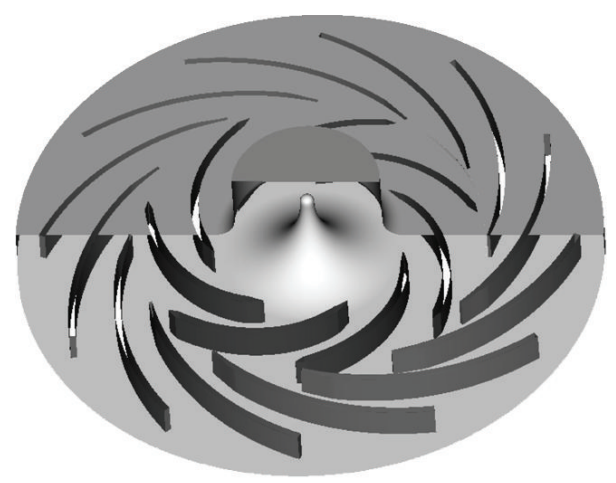

FIGURE 1: Geometry of the ERCOFTAC centrifugal pump.

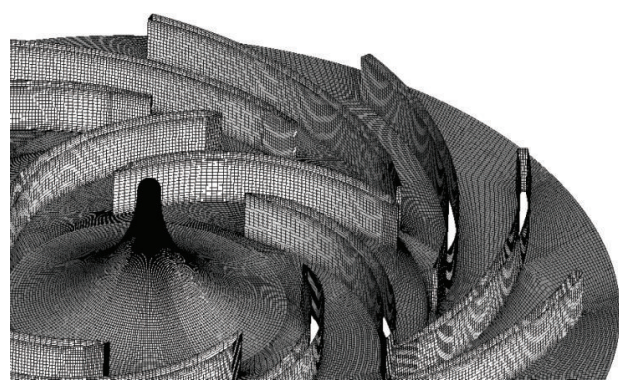

(a)

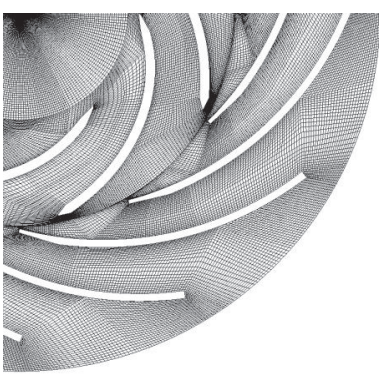

(b)

FIGURE 2: Computational mesh.

theoretical investigations of rotor flow and rotor-stator interaction. The original test case was presented by Combes [8] at the Turbomachinery Flow Prediction ERCOFTAC Workshop in 1999. Intensive studies were then carried out using proprietary CFD software. 2D numerical simulation was initially the only approach permitted by computer hardware limitations. Bert et al. [9] presented a 2D analysis of the ERCOFTAC centrifugal pump. Following the development of hardware, 3D unsteady studies were then done $[10,11]$. The geometry of the ERCOFTAC centrifugal pump is shown in Figure 1.

Large meshes and short time steps are often used in 3D unsteady calculations, making the simulations computationally heavy. Simulations of this kind are decomposed for parallel processing. This becomes costly when proprietary software is used, where there is an additional license cost for each process. To offer a viable alternative, the community-driven OpenFOAM Turbomachinery Working Group extends and validates OpenFOAM for turbomachinery applications [12]. OpenFOAM is an open source library written in $\mathrm{C}++$ [13]. It is based on the finite volume method and has proven to be as accurate as proprietary codes for many applications [14-16]. $2 \mathrm{D}$ numerical simulations of the ERCOFTAC centrifugal pump were previously made using OpenFOAM by Petit et al. [17]. The general behavior of the flow was well captured, but the results suggested the use of $3 \mathrm{D}$ simulations for better capturing the unsteadiness of the flow.

The present work reports the unsteady flow field of the ERCOFTAC centrifugal pump obtained by 3D steady and unsteady CFD calculation. The steady simulation uses the frozen rotor concept, where the results are a crude estimation of the ensemble-averaged flow for a fixed rotor position. A series of such snapshots gives an estimation of the unsteadiness of the flow in the pump. The unsteady simulation uses a fully resolved sliding grid approach. The unsteady flow is computed using four different turbulent models, the $k-\varepsilon$, the realizable $k-\varepsilon$, the RNG $k-\varepsilon$, and the $k-\omega$ SST. The results are analyzed and compared in detail with the measurements performed by Ubaldi et al. [3] in the radial gap between the impeller and diffuser. To this day, the present work is the most extensive and accurate comparison between experimental and numerical results of the ERCOFTAC centrifugal pump unsteady flow field. All the available experimental results are compared with the numerical results, to analyse the accuracy of the two main approaches used to simulate rotor-stator interaction. It is furthermore an open test case, that has been shared with the OpenFOAM community, and the results presented in the present work can be easily reproduced.

\section{Test Case and Operating Conditions}

The ERCOFTAC centrifugal pump test rig was built by Ubaldi et al. [3] and consists of a $420 \mathrm{~mm}$ diameter unshrouded centrifugal impeller and a $644 \mathrm{~mm}$ diameter radial vaned diffuser. Details on the geometry and coordinates of the impeller blade and diffuser vane profiles are given in Ubaldi et al. [3]. The impeller has 7 untwisted constant thickness 


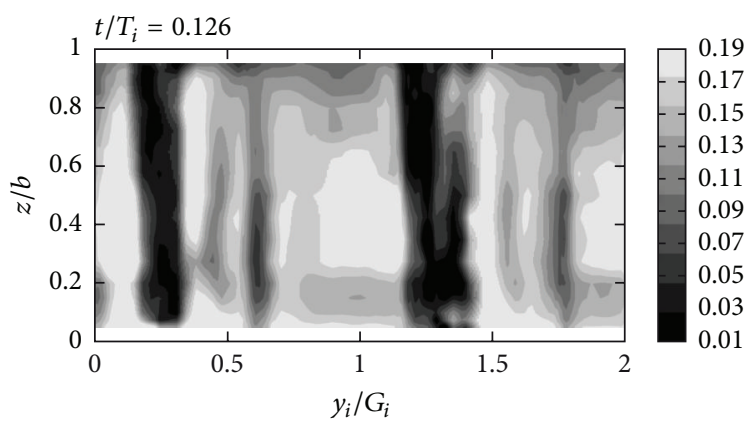

(a) Experimental

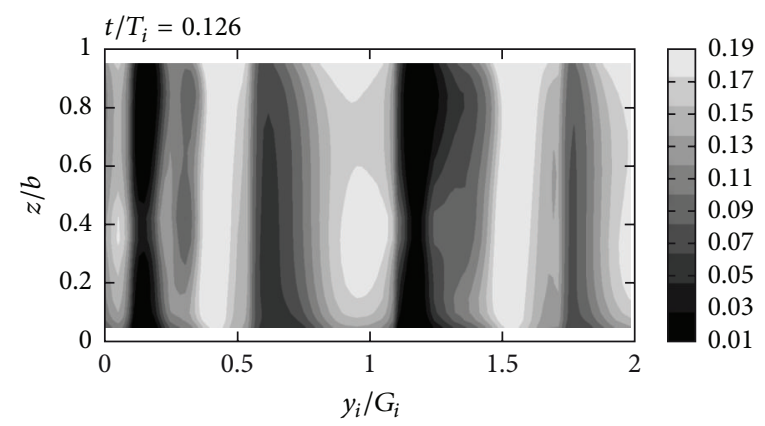

(b) Steady $k-\varepsilon$

FIGURE 3: Experimental and calculated radial velocities in the radial gap for the steady-state simulation using the $k-\varepsilon$ turbulence model.

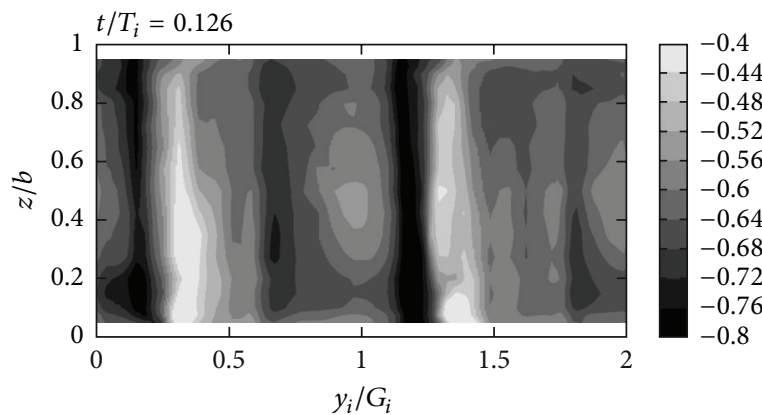

(a) Experimental

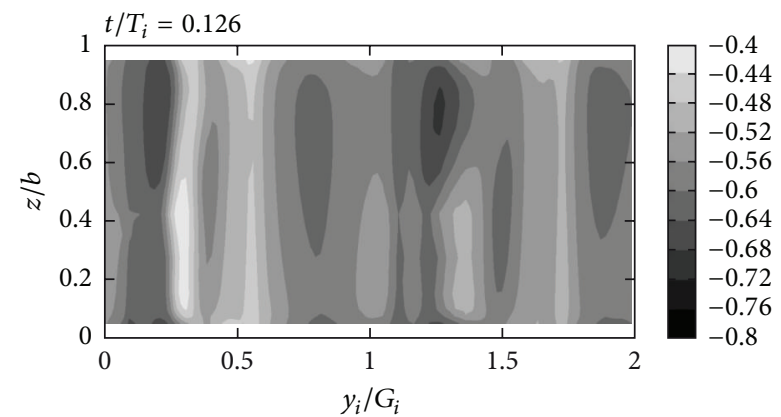

(b) Steady $k-\varepsilon$

FIGURE 4: Experimental and calculated tangential velocity fields in the radial gap for the steady-state simulation using the $k-\varepsilon$ turbulence model.

backswept blades, and the diffuser has 12 vanes. There is a $6 \%$ vaneless radial gap between the impeller and diffuser. The tip clearance can be varied but is set at a value of $0.4 \mathrm{~mm}$, corresponding to $1 \%$ of the blade span. The tip clearance is not included in the present simulations however.

The measuring techniques used were hot wire anemometry and fast-response pressure transducers. The hot wire probe was used to measure the unsteady $3 \mathrm{D}$ flow in the vaneless gap at a radial distance of $4 \mathrm{~mm}$ from the trailing edge of the blade and $8 \mathrm{~mm}$ from the leading edge of the vane. The unsteady static pressure was measured at the front cover facing the unshrouded impeller passages. The experiments were conducted at a constant rotational speed of $2000 \mathrm{rpm}$, at the nominal operating condition described in Table 1 . The model operates in an open air circuit directly discharged into the atmosphere from the radial diffuser. The inlet air temperature was $298 \mathrm{~K}$ and the air density was $1.2 \mathrm{~kg} / \mathrm{m}^{3}$.

\section{Computational Domain and Numerical Setup}

The meshes for the impeller and diffuser regions were generated separately; see Figure 2. Both of the mesh regions are block structured and were generated using the ICEM-CFD software, with $\mathrm{O}$-grids around the blades and the diffuser vanes and $\mathrm{H}$-grids in the blade passages. Angular geometrical periodicity is used to mesh the different blades. The mesh has
TABLE 1: Geometric data and operating conditions.

\begin{tabular}{ll}
\hline Impeller & \\
$D_{1}=240 \mathrm{~mm}$ & Inlet blade diameter \\
$D_{2}=420 \mathrm{~mm}$ & Outlet diameter \\
$b=40 \mathrm{~mm}$ & Blade span \\
$z_{i}=7$ & Number of blades \\
Diffuser & \\
$D_{3}=444 \mathrm{~mm}$ & Inlet vane diameter \\
$D_{4}=664 \mathrm{~mm}$ & Outlet vane diameter \\
$b=40 \mathrm{~mm}$ & Blade span \\
$z_{d}=12$ & Number of vanes \\
Operating conditions & \\
$n=2000 \mathrm{rpm}$ & Rotational speed \\
$U_{2}=43.98 \mathrm{~m} / \mathrm{s}$ & Impeller tip speed \\
$\varphi_{c}=0.0048$ & Flow rate coefficient \\
$\Psi_{c}=0.65$ & Total pressure rise coefficient \\
$\operatorname{Re}=6.5 * 10^{5}$ & Reynolds number \\
\hline
\end{tabular}

a total of 2074078 nodes. The angles of the cells are between $30^{\circ}$ and $140^{\circ}$ degrees, with $92 \%$ between $70^{\circ}$ and $100^{\circ}$. The $y^{+}$ values at the walls yield an average value of 50 .

The continuity equation and the 3D incompressible unsteady Reynolds-averaged Navier-Stokes equations are solved. The eddy-viscosity assumption is used to model the 


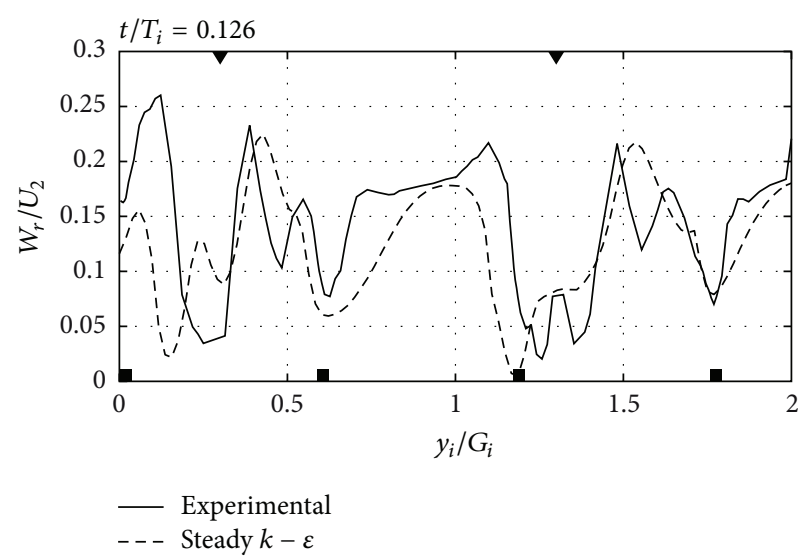

(a) Radial velocity

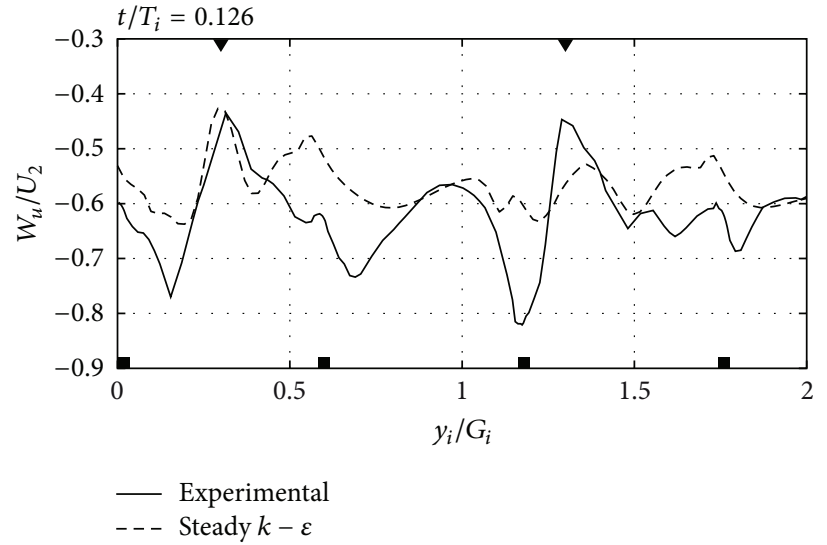

(b) Tangential velocity

FIGURE 5: Radial and tangential velocities at the impeller outlet at midspan for the steady-state simulation using the $k-\varepsilon$ turbulence model.

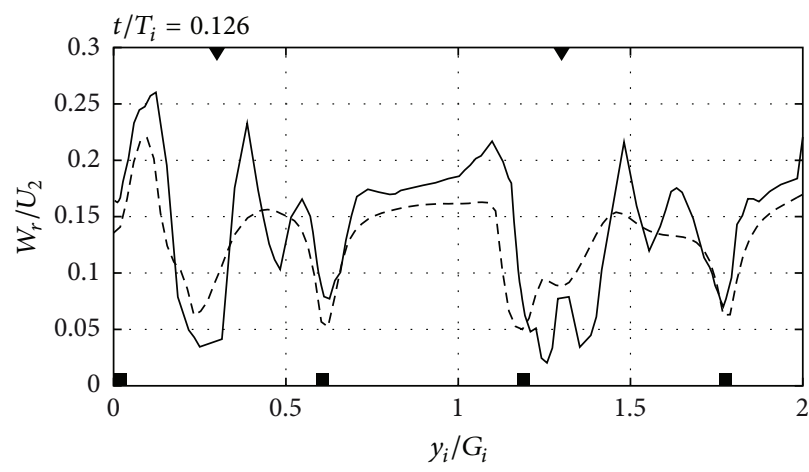

(a) $t / T_{i}=0.126$

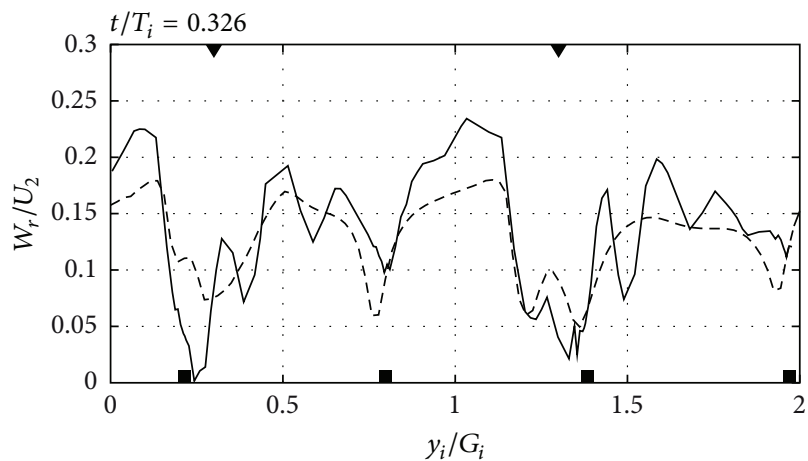

- Measurements

(c) $t / T_{i}=0.326$

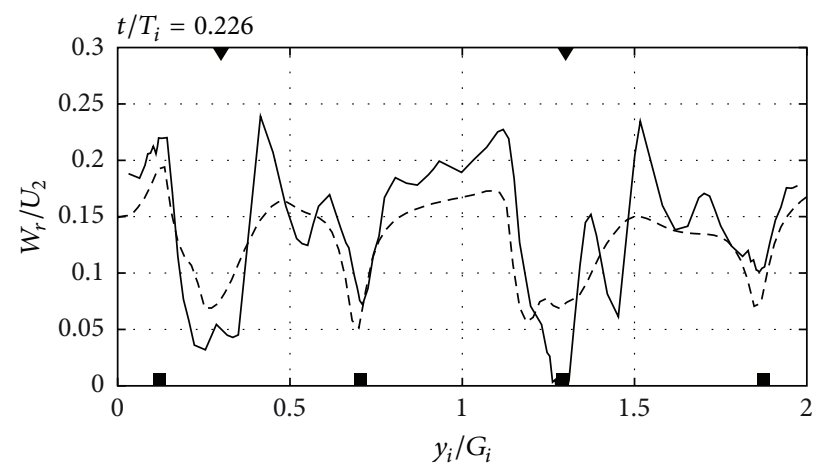

(b) $t / T_{i}=0.226$

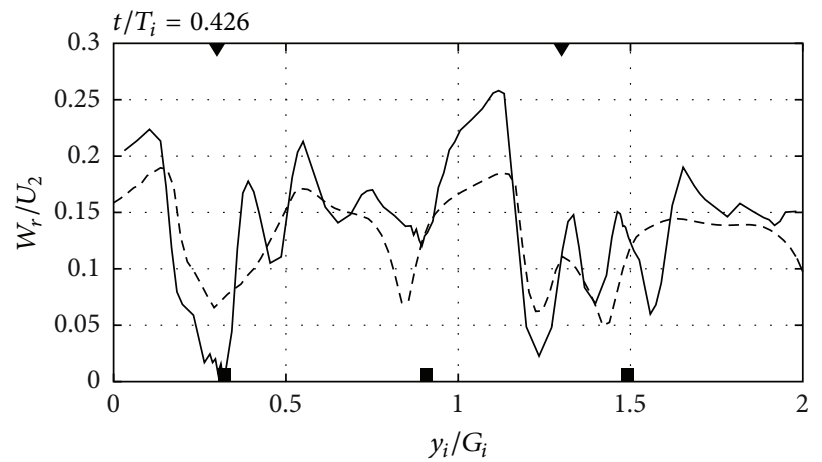

- Measurements

(d) $t / T_{i}=0.426$

FIGURE 6: Radial velocity in the radial gap $\left(R / R_{2}=1.02\right)$ at mid-span for the unsteady simulation using the $k-\varepsilon$ turbulence model.

turbulence Reynolds stress tensor, and the standard log-law wall function is used at the walls. A second-order, linearupwind scheme [18] is used to discretize the convection terms, and the second-order backward scheme is used to discretize the time derivative. The number of iterations in the transient SIMPLE algorithm at each time step is set to 10 . This number of iterations is enough to reduce the residuals by three orders of magnitude. The final residuals are below $10^{-6}$ except for the pressure, which has a final residual of $10^{-5}$. Based on the experimental measurements [3], the inlet velocity is set to a constant purely axial component, and the inlet turbulence intensity is assumed to be $5 \%$, with a viscosity ratio of 10 . At the outlet, all variables are given a zero gradient boundary condition, except for the pressure, which is set to 0 . 


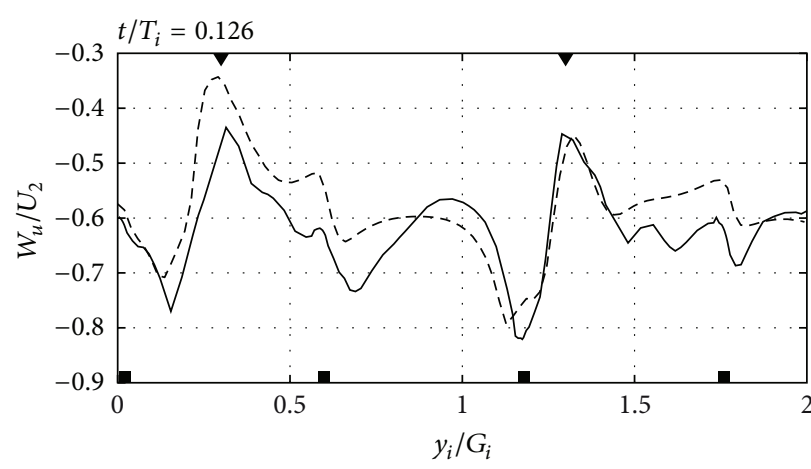

(a) $t / T_{i}=0.126$

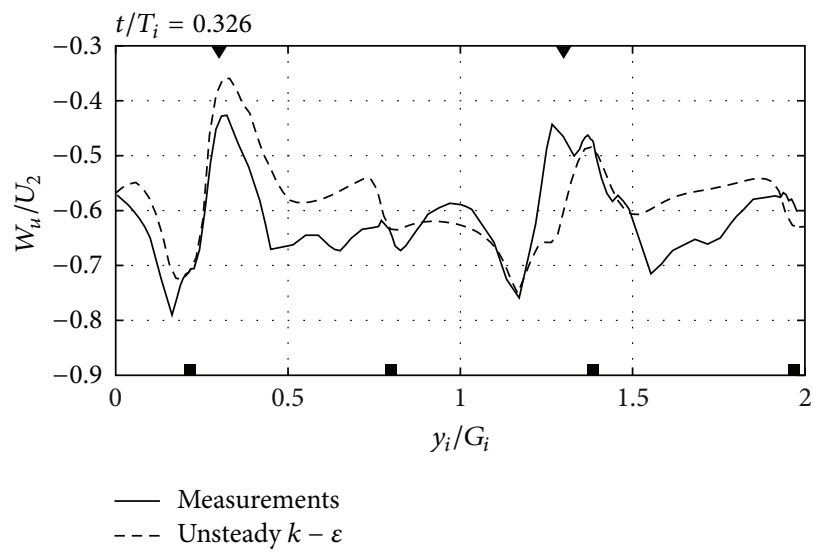

(c) $t / T_{i}=0.326$

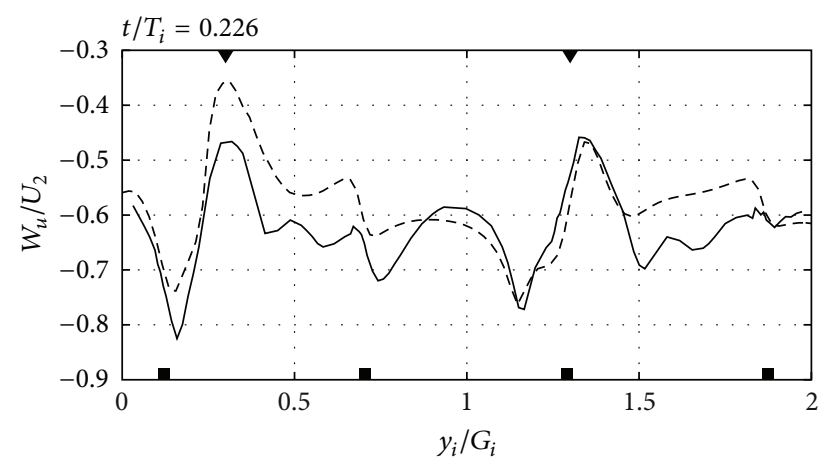

(b) $t / T_{i}=0.226$

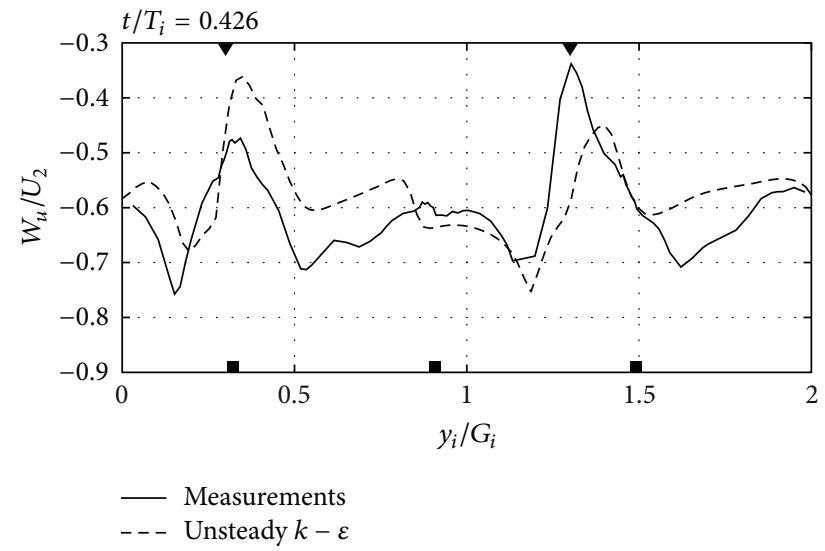

(d) $t / T_{i}=0.426$

FIGURE 7: Tangential velocity in the radial gap $\left(R / R_{2}=1.02\right)$ at mid-span for the unsteady simulation using the $k-\varepsilon$ turbulence model.

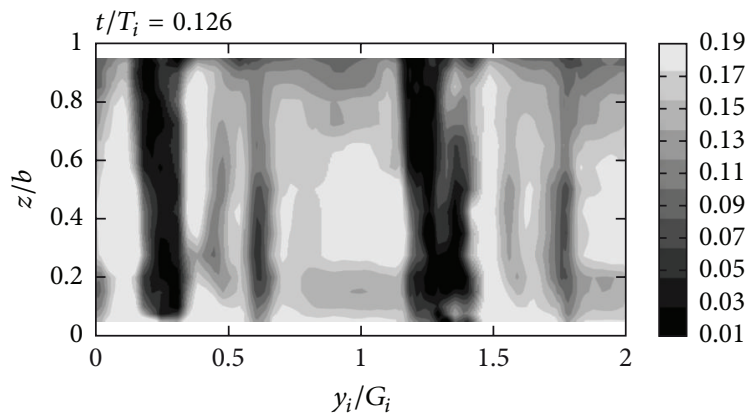

(a) Experimental

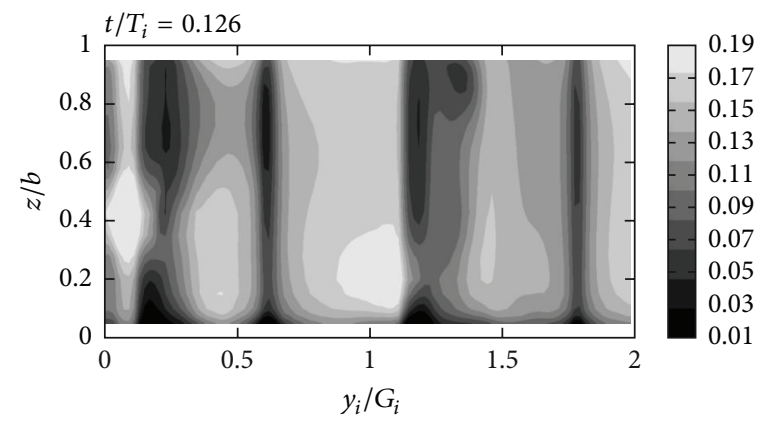

(b) Unsteady $k-\varepsilon$

FIGURE 8: Experimental and calculated radial velocities in the radial gap for the unsteady simulation using the $k-\varepsilon$ turbulence model.

The time step for the unsteady simulations was fixed to $7 e^{-5} \mathrm{~s}$, which gives a maximum Courant number of 6 . The calculations are carried out on a cluster, using 8 nodes equipped with 4 cores each. Using these parameters, one impeller rotation in the unsteady simulation takes 48 hours to compute.

Although the impeller tip clearance is a very important aspect of the geometry, it is not included in the computational model. The tip gap is $1 \%$ of the blade spade, that is to say, $0.4 \mathrm{~mm}$. To validate the log-law wall function used at the walls, the $y^{+}$values at the walls must yield a minimum value of 30. This in turn gives a limitation for the cells size at the walls bigger than $1 \%$ of the blade spade. It is thus very difficult to include the tip clearance in the computational domain when wall treatment is applied at the walls.

Two different rotor-stator interaction methods are used in this work. The first is a steady-state multiple frame of reference approach, where the impeller flow field is solved in a rotating frame of reference and the diffuser flow in a fixed frame of [17]. The local fluxes at the interface are transferred using a General Grid Interface (GGI), implemented in OpenFOAM by Beaudoin and Jasak [19] and validated by 2D 


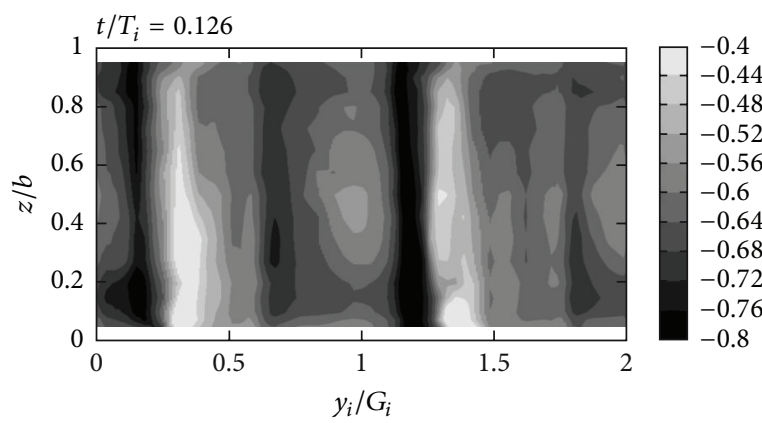

(a) Experimental

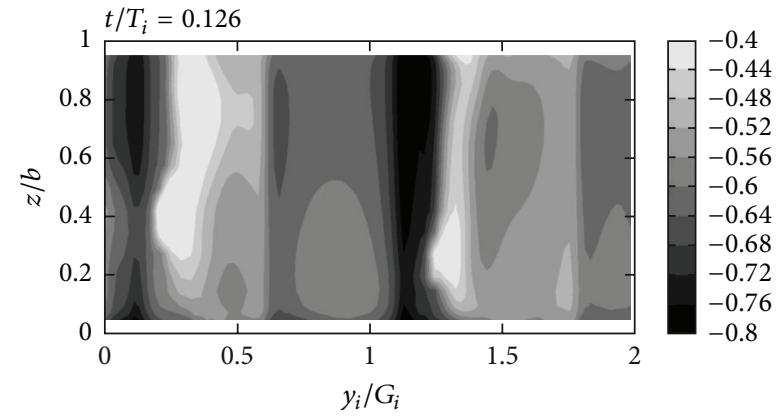

(b) Unsteady $k-\varepsilon$

FIGURE 9: Experimental and calculated tangential velocities in the radial gap for the unsteady simulation using the $k-\varepsilon$ turbulence model.

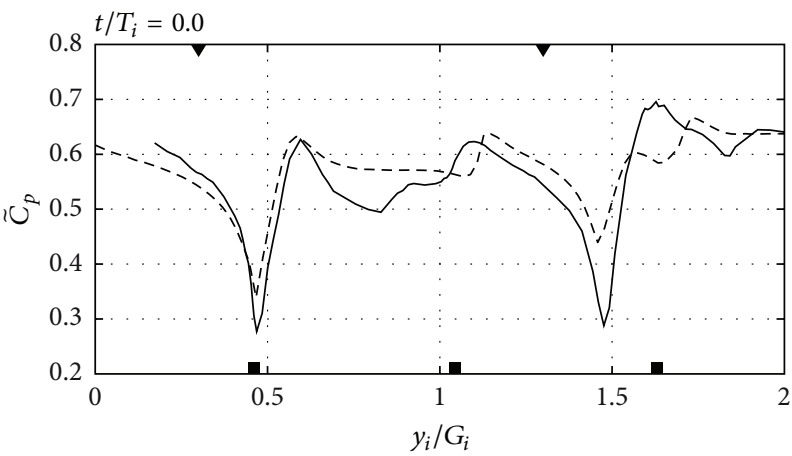

(a) $t / T_{i}=0.0$

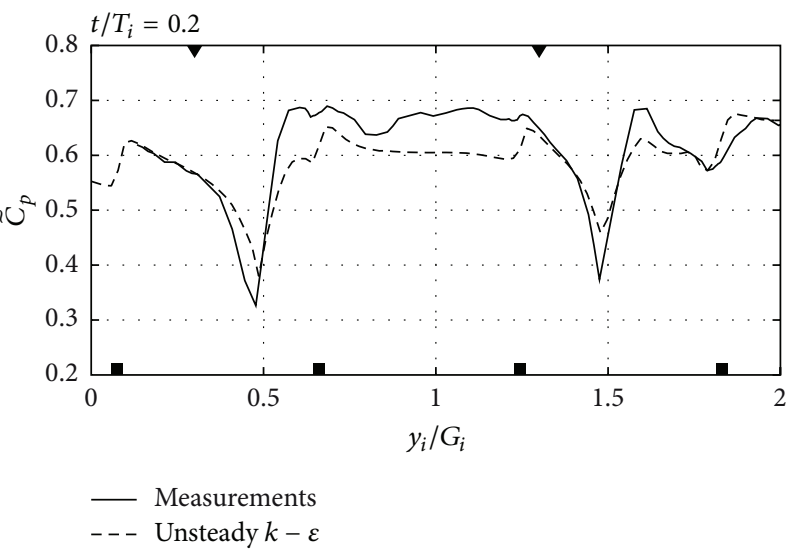

(c) $t / T_{i}=0.2$

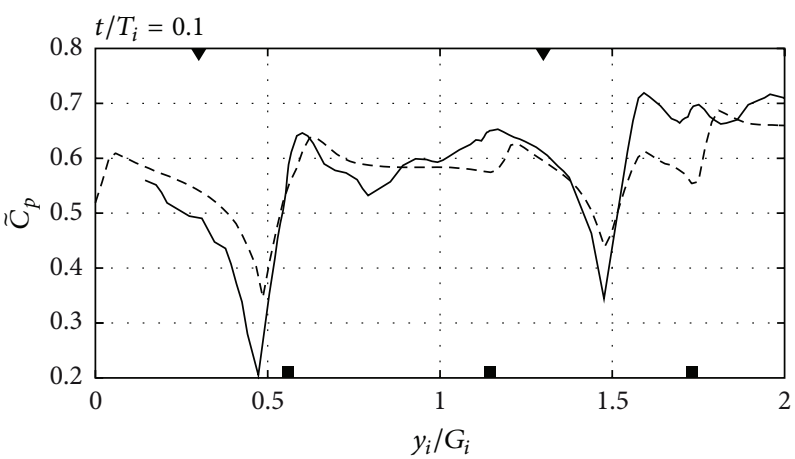

(b) $t / T_{i}=0.1$

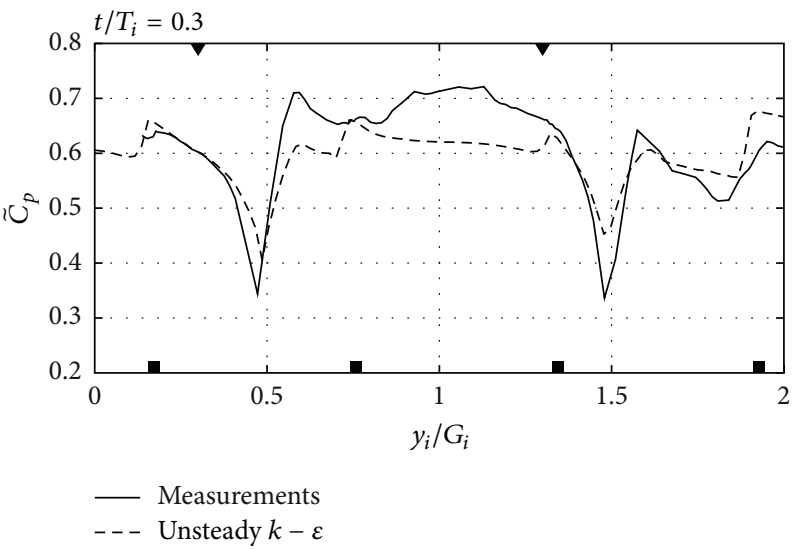

(d) $t / T_{i}=0.3$

FIGURE 10: Static pressure coefficient $\widetilde{C}_{p}$ in the radial gap $\left(R / R_{2}=1.02\right)$ at mid-span for the unsteady simulation using the $k-\varepsilon$ turbulence model.

simulations of the ERCOFTAC centrifugal pump [17]. It is a method commonly used in proprietary CFD codes, where it is referred to as frozen rotor. This approach resembles a snapshot of the flow, frozen in time, thus failing to predict the unsteadiness of the flow between the diffuser vanes. It also gives an incorrect advection of the impeller wakes in the vaned diffuser. It is a fast preliminary method, however, and gives satisfying results in the radial gap between the impeller and diffuser [20] that can also serve as a good initial condition for unsteady simulations. The second rotor-stator interaction method resolves the flow unsteadiness using a sliding grid approach. This transient method rotates the impeller part of the mesh with respect to the stator part at each time step. In this case, the local fluxes are also transferred using the GGI interface, which is updated every time step. The interaction between the impeller and diffuser is thus fully resolved. The chosen time step corresponds to a rotation of the impeller of about $0.84^{\circ}$. Previous studies have shown that this angular time step is sufficient to allow the transient solver to catch the unsteadiness of the flow [21]. 

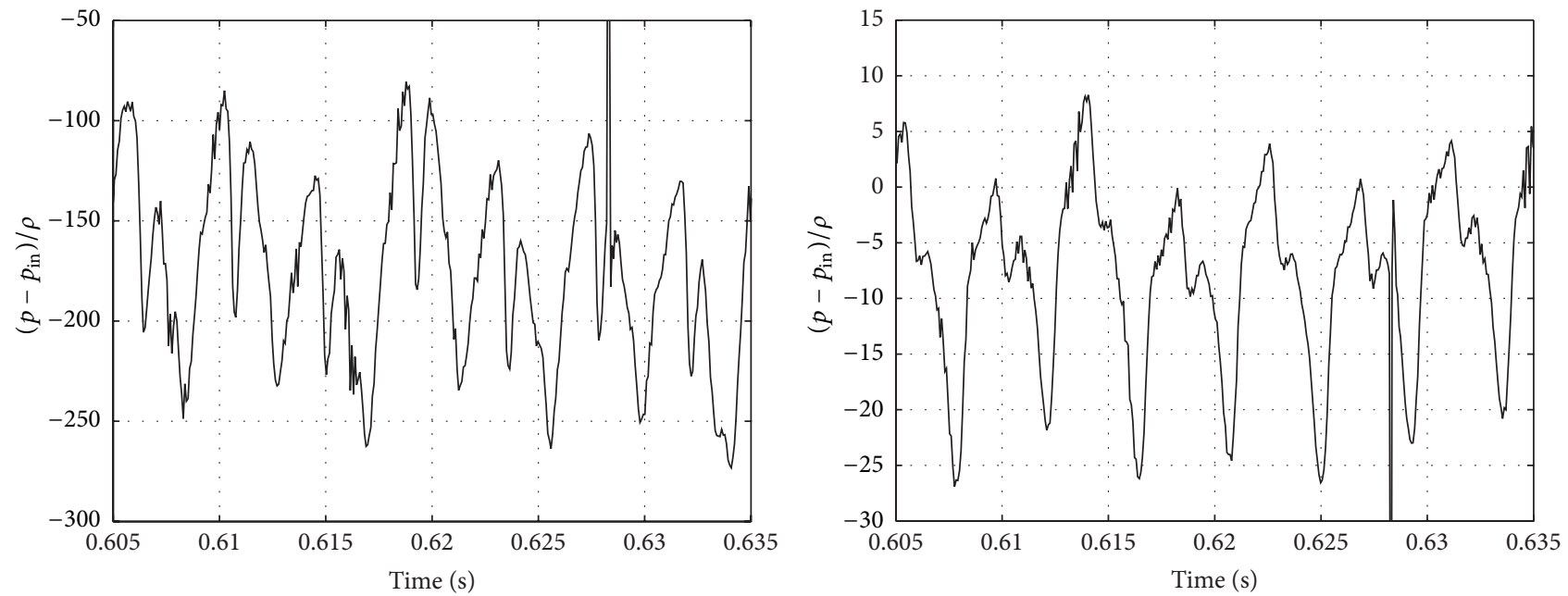

(a) Original signal

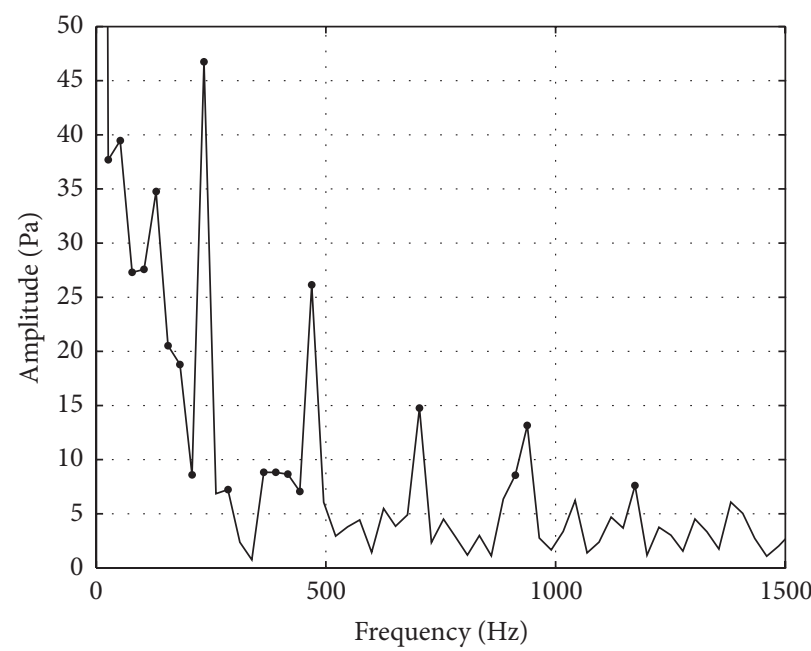

— Full spectrum

- Selected frequencies

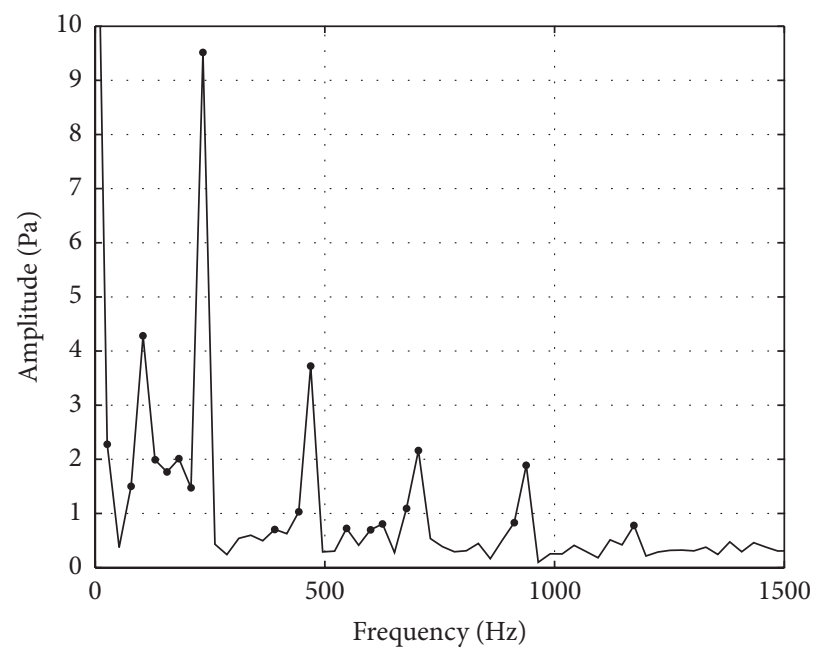

— Full spectrum

- Selected frequencies

(b) Fourier transform
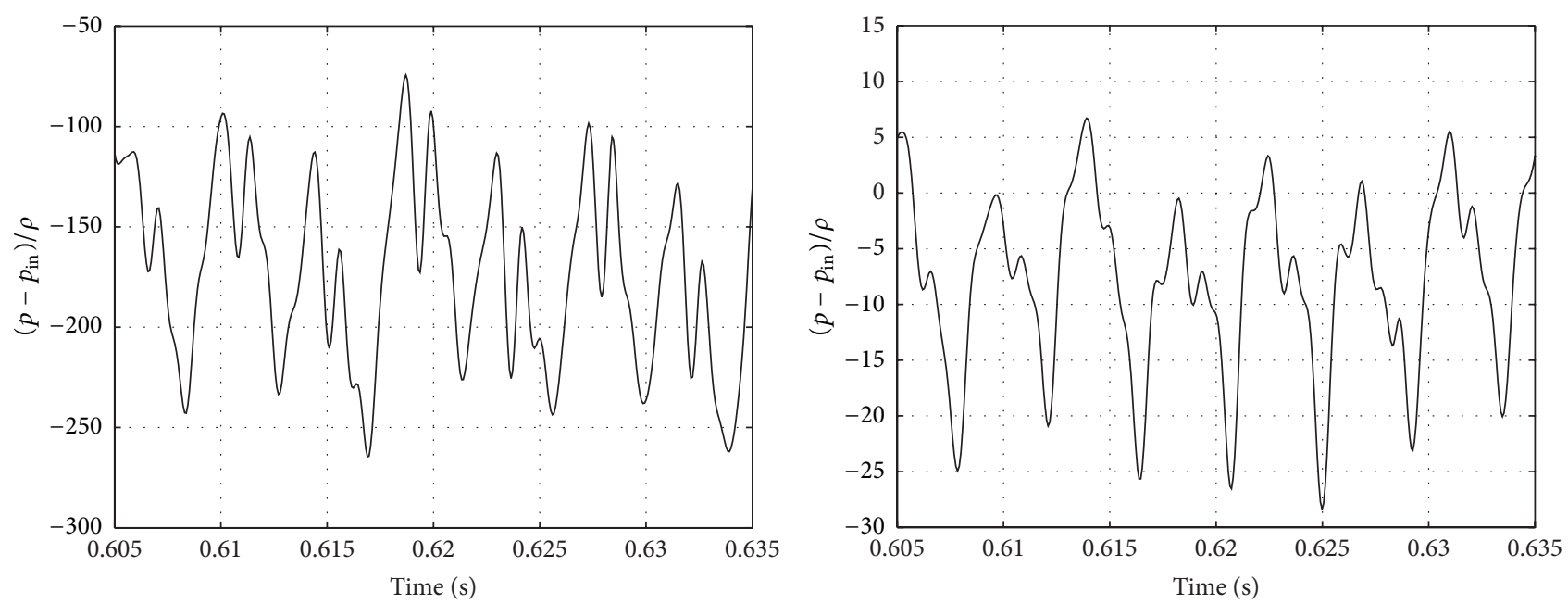

(c) Reconstructed signal

FIGURE 11: Pressure signal for the probe located at the outlet of the impeller (left) and at the outlet of the diffuser (right). The signal in (c) is reconstructed using the 20 main frequencies selected in (b). 


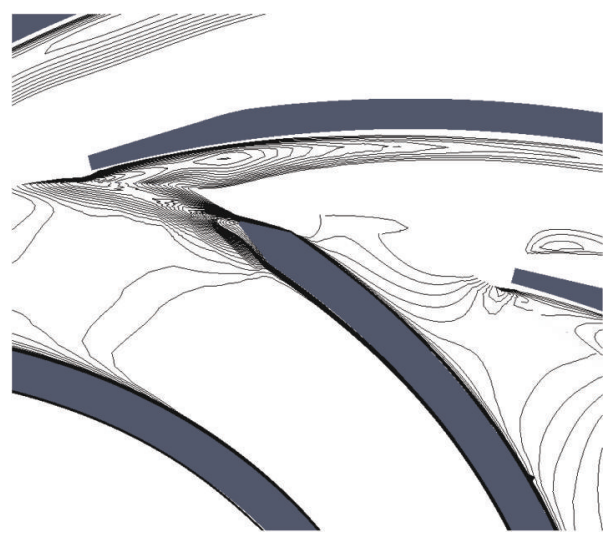

(a) Frozen rotor
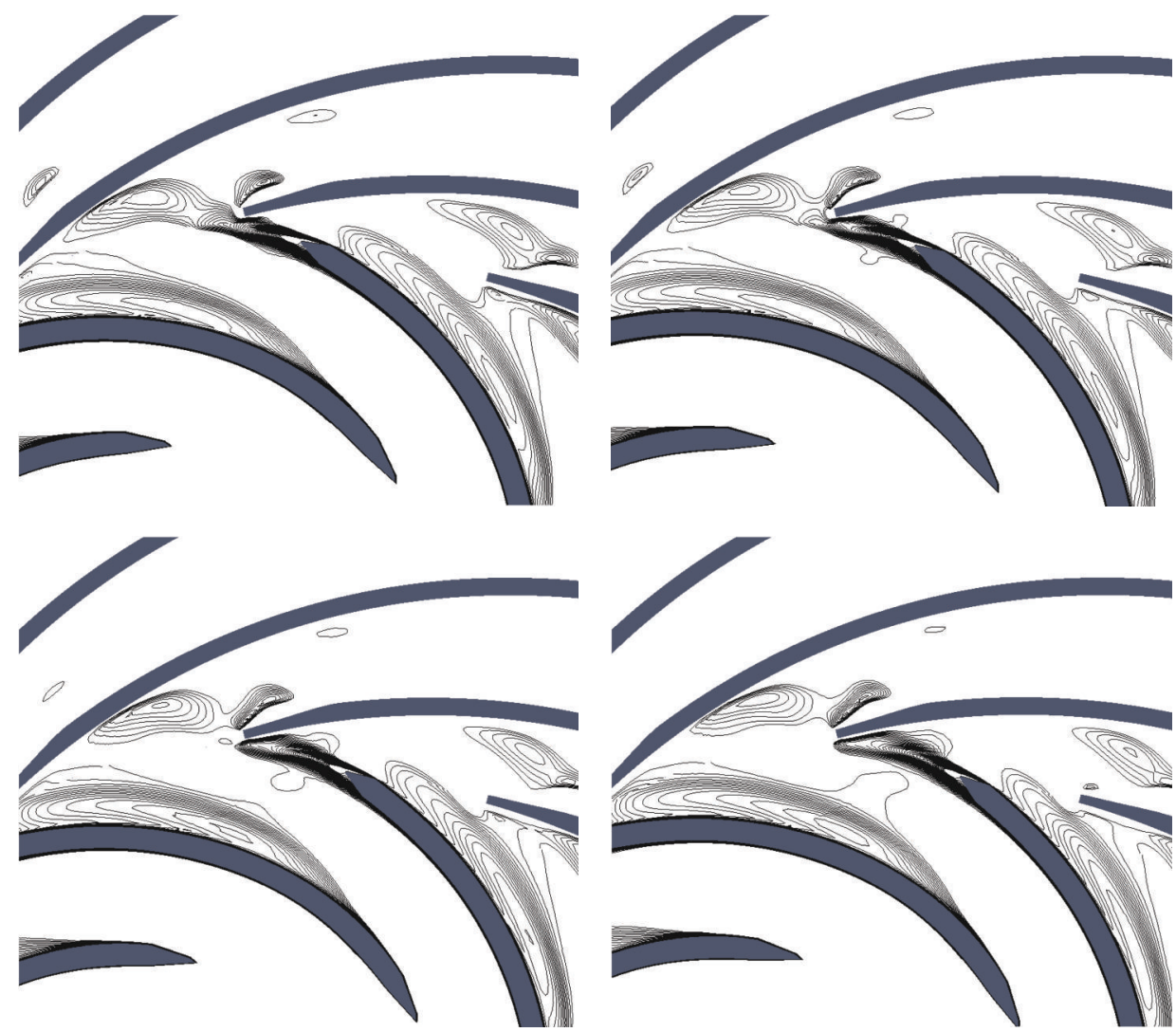

(b) Sliding grid, for four different positions of the runner blades relative to the diffuser vanes

FIGURE 12: Prediction of the wake behind the impeller for the frozen rotor and sliding grid approaches.

The results from two different rotor-stator interaction approaches are first compared with each other and with the measurement database, using the standard $k-\varepsilon$ turbulence model to model the eddy-viscosity. A comparison is then made of the results from four different turbulence models. An extensive comparison of the different RANS turbulence models available in OpenFOAM was made by Moradnia [22]. The focus in Moradnia's study was particularly on the highand low-Reynolds-number two-equation eddy-viscosity turbulence models and on the Reynolds stress transport turbulence models. The conclusion of the study by Moradnia was that the four high Reynolds turbulence models were better at predicting the flow while preserving numerical stability and efficiency. These are the $k-\varepsilon$ [23], the realizable $k-\varepsilon$ [24], the RNG $k-\varepsilon$ [25], and the $k-\omega$ SST [26] turbulence models. The $k-\omega$ SST is used in combination with the standard loglaw wall function at the walls. These models were thus been chosen for comparisons in the present work.

\section{Results and Discussion}

The following sections present and discuss the results of the steady and unsteady rotor-stator interaction approaches 


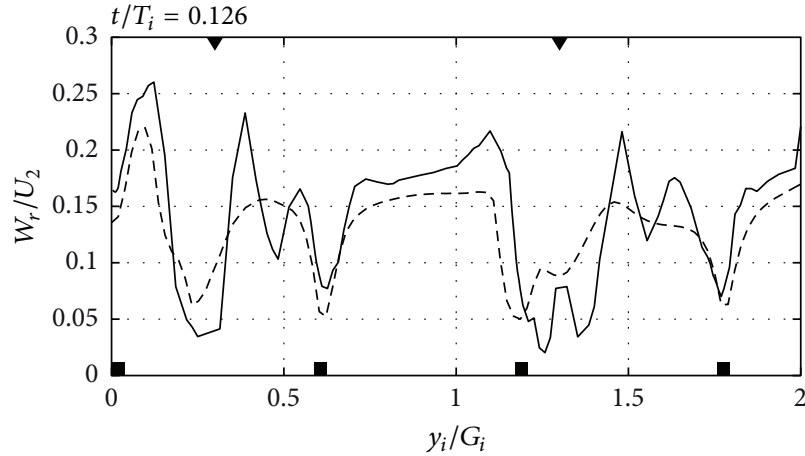

- Measurements - - Unsteady $k-\varepsilon$

(a) Unsteady $k-\varepsilon$

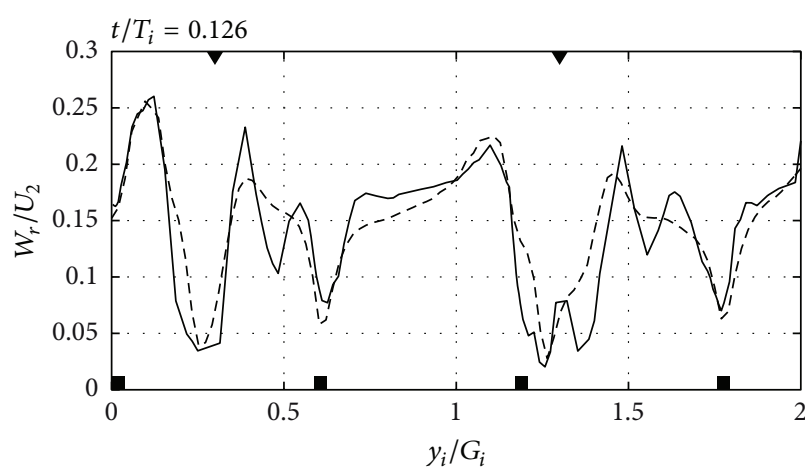

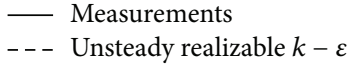

(c) Unsteady realizable $k-\varepsilon$

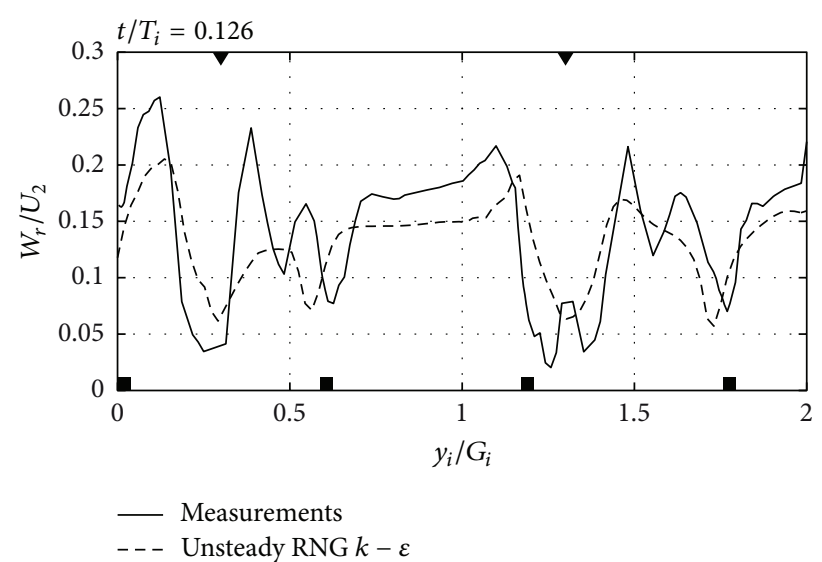

(b) Unsteady RNG $k-\varepsilon$

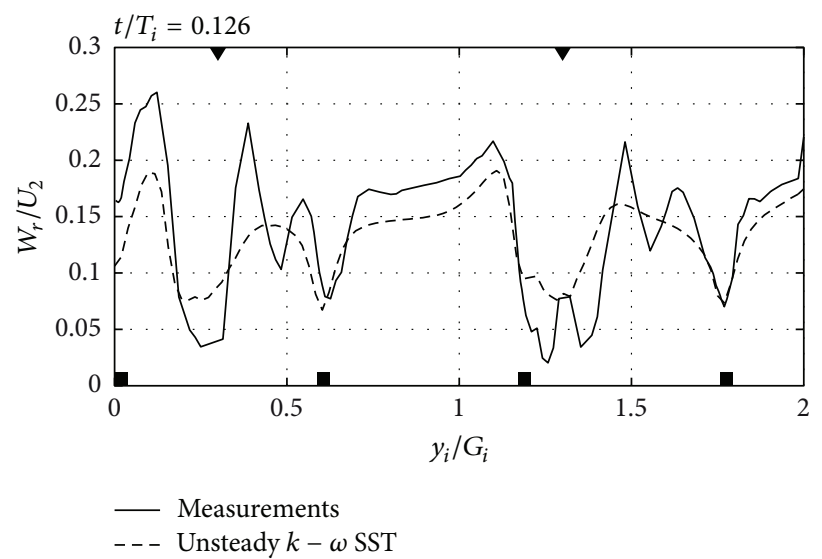

(d) Unsteady $k-\omega \mathrm{SST}$

FIGURE 13: Radial velocity in the radial gap $\left(R / R_{2}=1.02\right)$ at mid-span.

using the standard $k-\varepsilon$ turbulence model. The results are compared with the experimental database. We also discuss the main differences between the results from the frozen rotor and sliding grid approaches. Finally, comparisons of the unsteady results using four turbulence models, $k-\varepsilon$, realizable $k-\varepsilon$, RNG $k-\varepsilon$, and $k-\omega$ SST, are presented.

All the kinematic quantities are normalized with the rotor tip speed, $U_{2}$. The circumferential rotor relative coordinate, $y_{i}$, and the axial coordinate, $z$, are made nondimensional by means of the circumferential pitch of the rotor, $G_{i}=2 \pi r / z_{i}$, and the blade span at the rotor outlet, $b$, respectively. The velocity comparisons are made at midspan in the radial gap, at a radius of $1.02 * R_{2}$. The time, $t$, is normalized by the rotor blade passing period, $T_{i}$. Triangles and squares in the plots describe the positions of the impeller blades and diffuser vanes, respectively. The results are observed in the relative frame, such that the impeller blades (triangles) have a fixed position in time, while the diffuser vanes (square) move from left to right.

4.1. Steady-State Results with the $k-\varepsilon$ Turbulence Model. Figures 3 and 4 show the ensemble-averaged experimental and calculated radial and tangential velocities in the radial gap at
$R=1.02 * R_{2}$ over two impeller pitches between the hub $(z / b=0.05)$ and the shroud $(z / b=0.95)$. The behavior of the flow is roughly captured by the simulation. However, a shift of the predicted wakes can be observed in Figure 4. Figure 5 extracts the same results at mid-span $(z / b=0.5)$. Although the radial velocity is reasonably well predicted, the phase shift can also be observed. The tangential velocity is incorrectly predicted after the rotor blade passage, as the wake remains at the same place, and aligns with the local relative streamlines, instead of being adverted into the diffuser vanes channel and dissolving.

$t / T_{i}$ represents the position of the impeller blade relative to the diffuser vane. For steady simulation, $t / T_{i}$ does not vary over time. The rotor part of the mesh must be rotated to get a new position for the impeller blade, and the flow must be computed once again. A sequence of many steady simulations with different angular positions for the impeller blades will then give a sequence of snapshots of the unsteadiness of the flow.

4.2. Unsteady Results with the $k-\varepsilon$ Turbulence Model. The instantaneous distributions of the ensemble-averaged radial and tangential velocity in the radial gap at mid-span when 


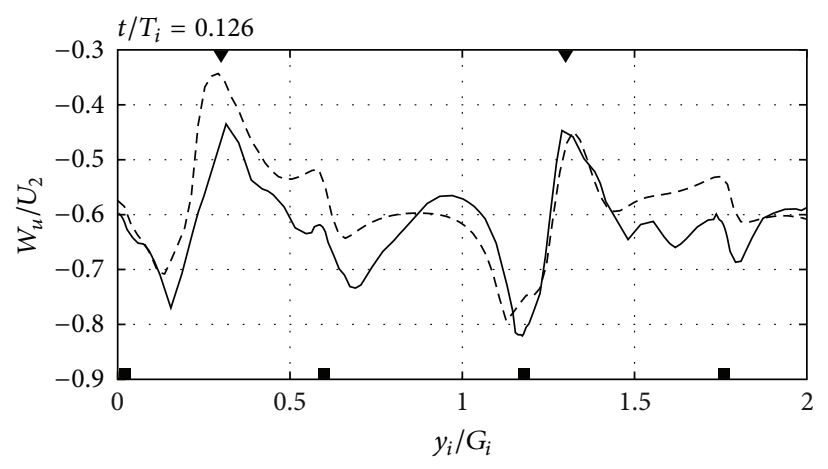

- Measurements
- - Unsteady $k-\varepsilon$

(a) Unsteady $k-\varepsilon$

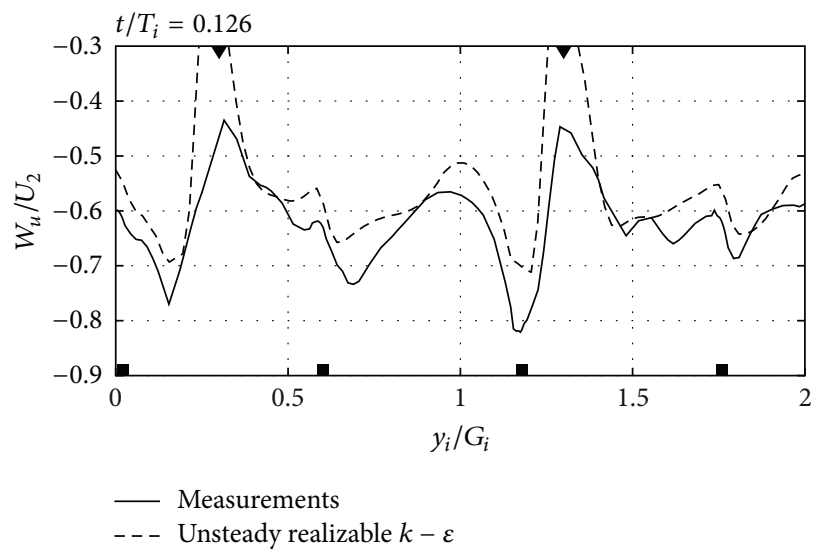

(c) Unsteady realizable $k-\varepsilon$

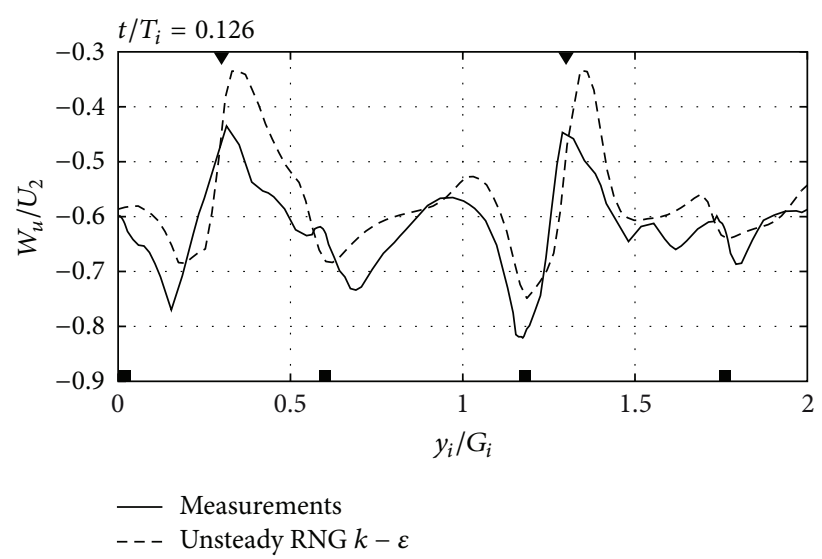

(b) Unsteady RNG $k-\varepsilon$

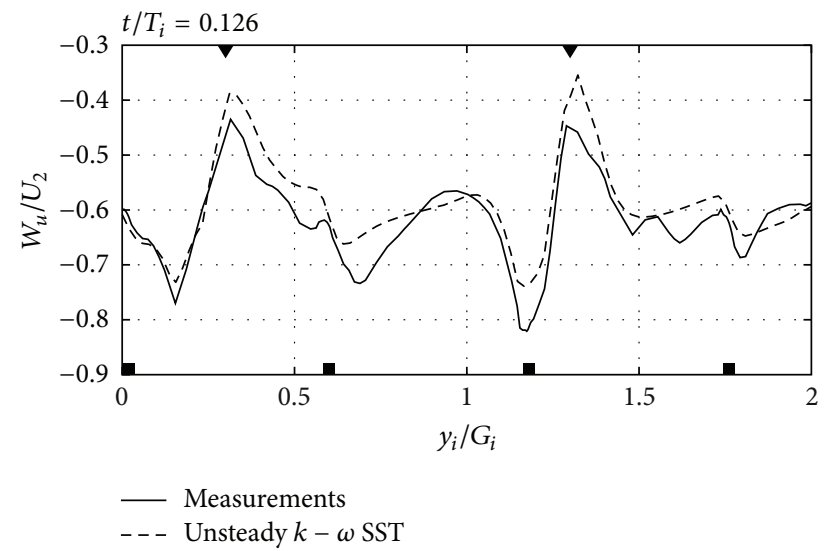

(d) Unsteady $k-\omega \mathrm{SST}$

FIGURE 14: Tangential velocity in the radial gap $\left(R / R_{2}=1.02\right)$ at mid-span.

using the $k-\varepsilon$ turbulence model are presented in Figures 6 and 7 , respectively. The calculated profiles are in good agreement with the measurements. They show a good prediction of the wake position and of the potential interaction linked to the diffuser vane leading edge, corresponding to low radial velocity peaks. However, some differences are still visible. The calculations overpredict the maximum of the wake for the tangential velocity, and a slight phase shift is still visible at the maximum of the wakes. This can be explained by Figures 8 and 9 , where it can be seen that the wakes predicted by the calculation are orthogonal to the shroud, while the measured ones are slightly inclined. This creates a phase shift at mid-span. A comparison of the static pressure is presented in Figure 10. The general evolution of the pressure is well predicted, but a slight phase shift is also present, and the global fluctuation of the mean pressure level is not accurately predicted. It is important to remember that some secondary flows were not included in this calculation. For example, Ubaldi et al. [6] explained that the low-pressure region located in the blade passage near the suction side seemed to be caused by the tip clearance vortex.

Figure 11(a) shows the pressure signals obtained by two probes located in the radial gap and at the outlet of the diffuser. The frequency contents of the signals are shown in Figure 11(b). The reconstructed signals using selected frequencies are shown in Figure 11(c). The frequency of the rotor is $f_{r}=2000 / 60=33.3 \mathrm{~Hz}$. The frequency of the impeller blades is $f_{i}=f_{r} * z_{i}=232 \mathrm{~Hz}$ and that of the diffuser vanes is $f_{d}=f_{r} * z_{d}=400 \mathrm{~Hz}$. The signal in the radial gap is dominated by the impeller blades' frequency and its multiples, $f_{i}$; see Figure 11(b). The impeller wakes are high-energy regions and decay very rapidly in the radial gap. At the outlet of the diffuser, a similar signal is shown in Figure 11(c), but a reduction in amplitudes with values lower than those found in the pump is apparent.

4.3. Comparison of the Frozen Rotor and Sliding Grid Approaches. Figure 12 illustrates the main difference between the frozen rotor and sliding grid results. The velocity magnitude behind the rotor blades in the frozen rotor simulation is shown in Figure 12(a). Figures 12(b) and 12(b) show the velocity magnitude behind the rotor blades at different time steps for the sliding grid approach. The wakes in the frozen rotor simulation suddenly change direction when they enter the absolute frame of reference, in the impeller region. The wakes are aligned with the local streamlines, which is a fundamental 


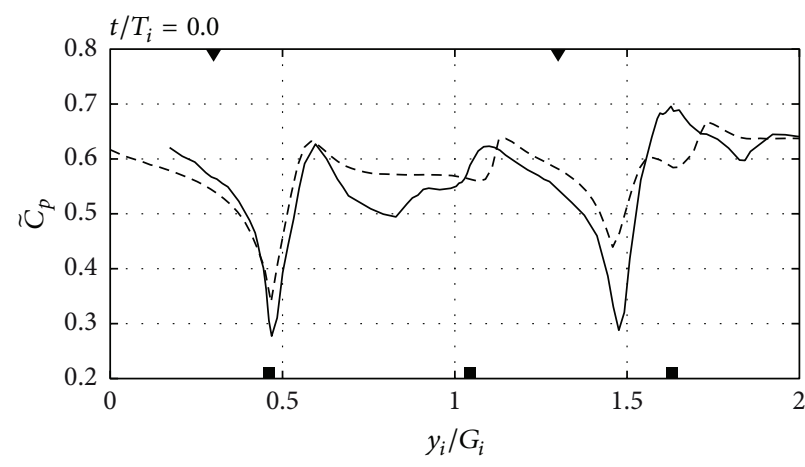

- Measurements --- Unsteady $k-\varepsilon$

(a) Unsteady $k-\varepsilon$

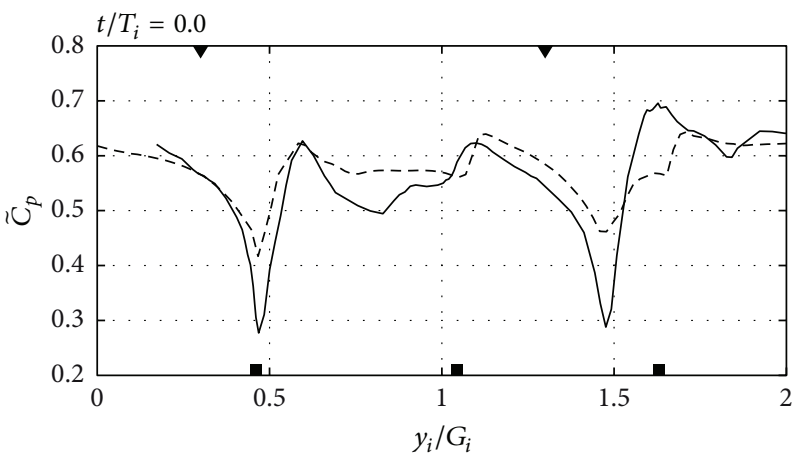

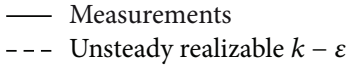

(c) Unsteady realizable $k-\varepsilon$

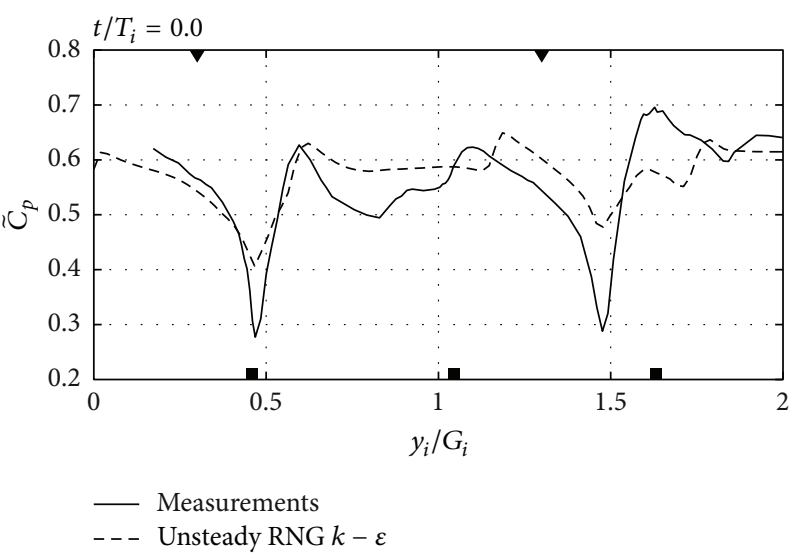

(b) Unsteady RNG $k-\varepsilon$

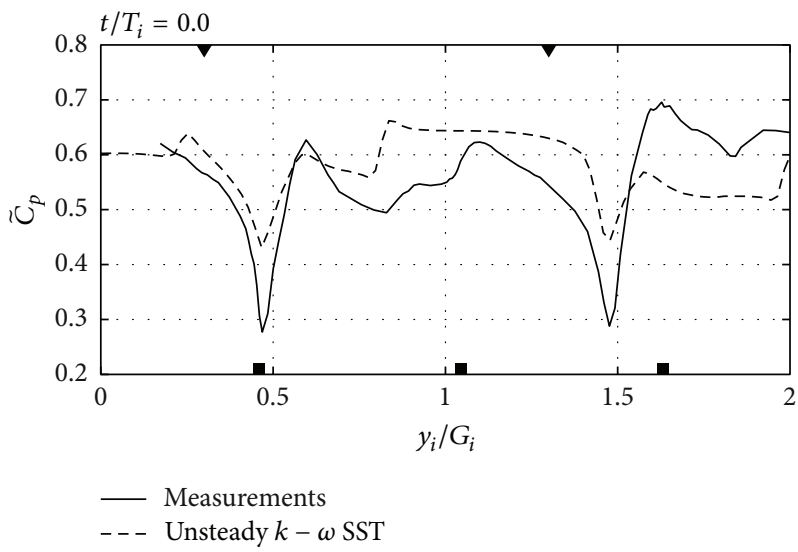

(d) Unsteady $k-\omega \mathrm{SST}$

FIGURE 15: Static pressure coefficient, $\widetilde{C}_{p}$, in the radial gap $\left(R / R_{2}=1.02\right)$ at mid-span.

problem with the frozen rotor concept. The wakes advected in the sliding grid approach do not change direction when they enter the diffuser region but are advected in the diffuser vane passages and cut by the diffuser vanes.

4.4. Comparison between Four Turbulence Models. The four two-equation turbulence models, $k-\varepsilon$ [23], realizable $k-\varepsilon$ [24], RNG $k-\varepsilon$ [25], and $k-\omega$ SST [26], used with the sliding grid approach are here compared for one position of the impeller blades with respect to the diffuser. The position differs for the pressure and velocity comparisons since Ubaldi et al. presented the velocity measurements for $t / T_{i}=0.126$ and the pressure measurements for $t / T_{i}=0$. Figures 13 and 14 show that all four turbulence models predict the flow distribution very well. The differences between the numerical and experimental results may be explained by the lack of tip clearance secondary flow in the numerical model, as suggested by Ubaldi et al. [3]. It is interesting to note that the calculation using the realizable $k-\varepsilon$ turbulence model very accurately predicts the maximum and minimum peak values of the wakes for the radial velocity, although the wakes are thinner than the ones of the experimental results. However, the tangential velocity in the impeller wakes is largely overpredicted when the realizable $k-\varepsilon$ turbulence model is used. Figure 15 shows that all four turbulence models predict the pressure drop in the wakes behind the impeller but fail to predict the pressure fluctuations in the diffuser vanes passage. In general, the four different turbulence models seem to overpredict the tangential velocity, as shown in Figure 16. This could be explained by the lack of leakage flow, as well as the use of the wall function approach, which fails to predict an accurate boundary layer flow. Figure 17 shows that all the models predict the large radial velocity at mid-span near the pressure side of the blades. This was not predicted at all in previous studies by Combès et al. [27] and Petit et al. [17]. The calculations made with the $k-\varepsilon$ and the RNG $k-\varepsilon$ turbulence models predict this feature in the lower part of the channel rather than that centered in the mid-span, as shown in Figure 17.

\section{Conclusion}

3D steady and unsteady simulations were carried out with the OpenFOAM CFD tool to study rotor-stator interaction in a centrifugal pump with a vaned diffuser. The four basic turbulence models, $k-\varepsilon$, realizable $k-\varepsilon$, RNG $k-\varepsilon$, and 


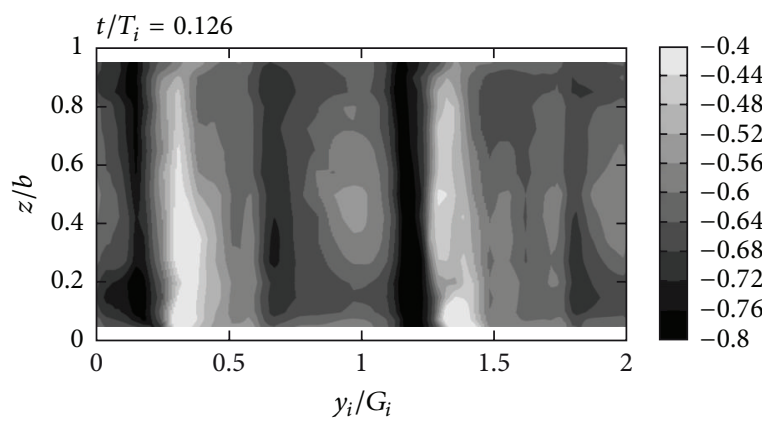

(a) Experiment

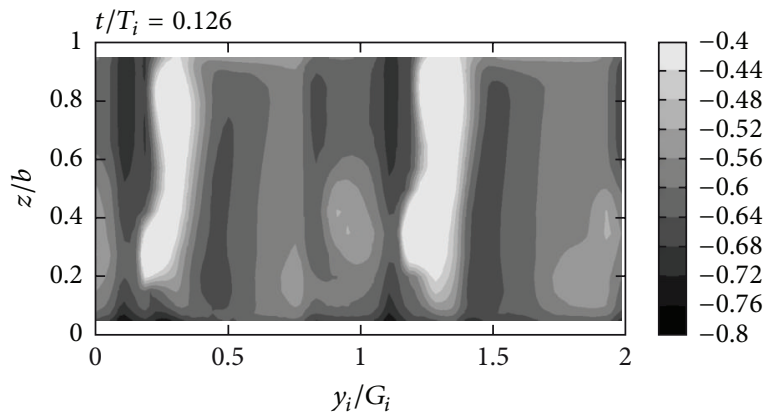

(c) Unsteady RNG $k-\varepsilon$

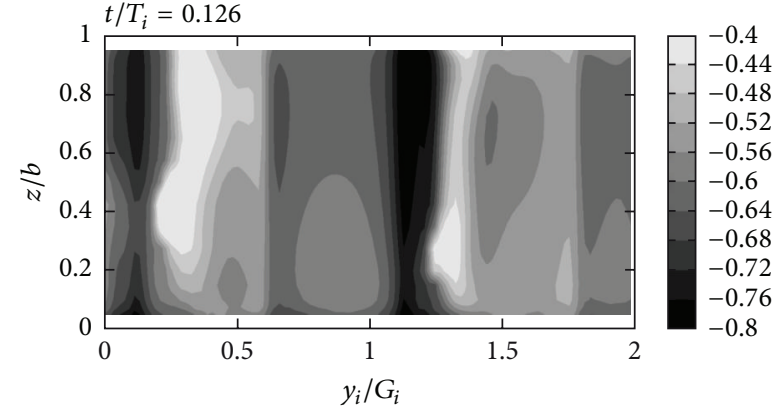

(b) Unsteady $k-\varepsilon$

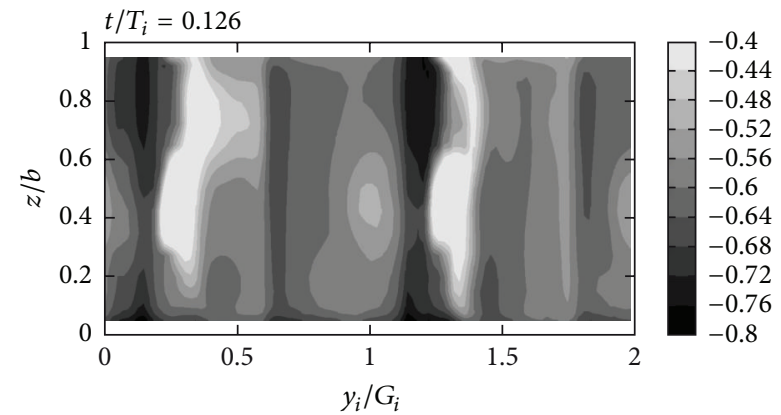

(d) Unsteady realizable $k-\varepsilon$

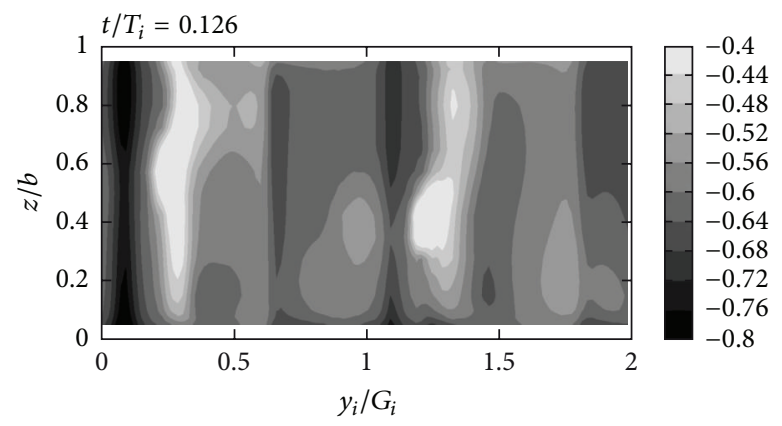

(e) Unsteady $k-\omega$ SST

FIGURE 16: Tangential velocities in the radial gap $\left(R / R_{2}=1.02\right)$.

$k-\omega$ SST, were used to perform calculations. The results were compared with the experimental investigation presented by Ubaldi et al. [3]. Although the secondary leakage flow was not included in the numerical model, the results show qualitatively good agreement with the experimental results.

The steady numerical simulation with the $k-\varepsilon$ turbulence model shows reasonably good agreement with the measurements, although it obviously does not predict the important unsteadiness. The numerical results in the radial gap yield good agreement with the experimental ones, but the flow in the diffuser passage is incorrectly predicted. The corresponding unsteady simulation resolves most of the unsteadiness and accurately predicts the behavior of the flow. Analyzing the pressure signals at the impeller and diffuser exits, it was observed that the impeller wakes are advected to the exit of the diffuser.

The results of four different turbulence models were compared with the experimental results. The turbulent models yield slightly different results but predict the flow unsteadiness at the same level of accuracy.

To further improve the numerical results, the leakage flow between the impeller blades and the shroud should be taken into account. Large eddy simulation (LES) or hybrid methods such as detached eddy simulation (DES) are suggested to more accurately resolve the flow unsteadiness.

\section{Nomenclature}

$D_{1}$ : Impellerinlet diameter $(\mathrm{mm})$

$D_{2}$ : Impeller outlet diameter $(\mathrm{mm})$

$\mathrm{D}_{3}$ : Diffuser inlet diameter $(\mathrm{mm})$

$D_{4}$ : Diffuser outlet diameter $(\mathrm{mm})$

$b$ : Impeller blade span ( $\mathrm{mm}$ )

$U_{2}$ : Impeller trailing edge velocity $(\mathrm{m} / \mathrm{s})$

$z_{d}$ : Number of diffuser vanes

$z_{i}$ : Number of impeller blades 


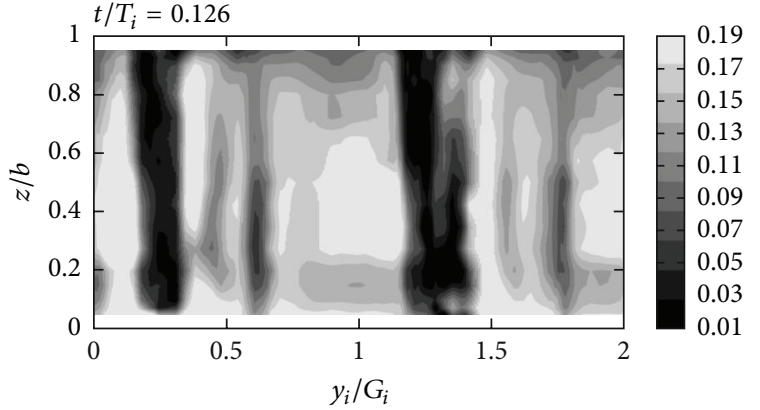

(a) Experiment

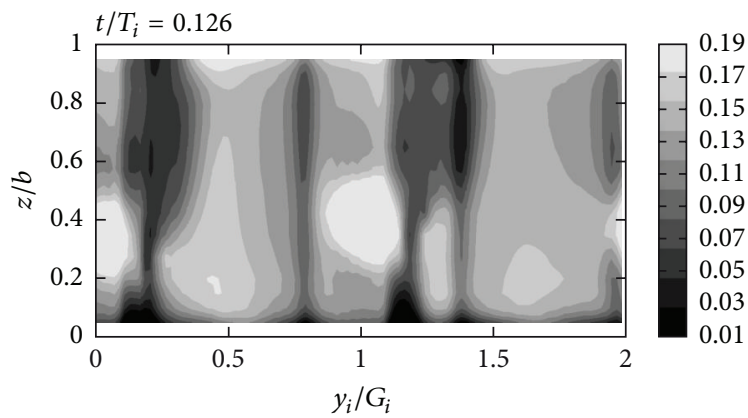

(c) Unsteady RNG $k-\varepsilon$

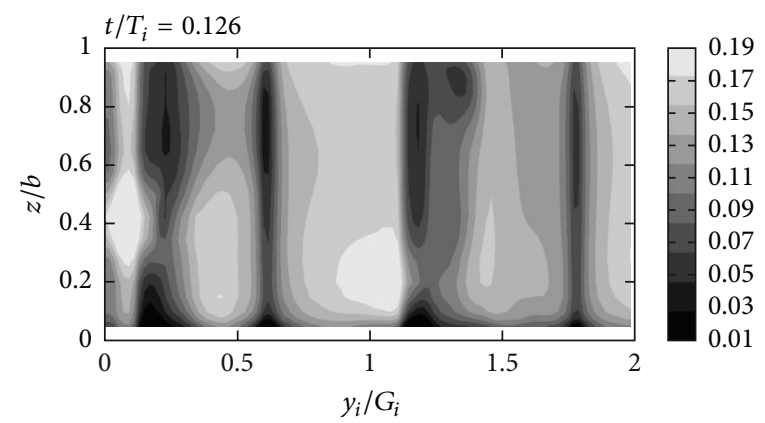

(b) Unsteady $k-\varepsilon$

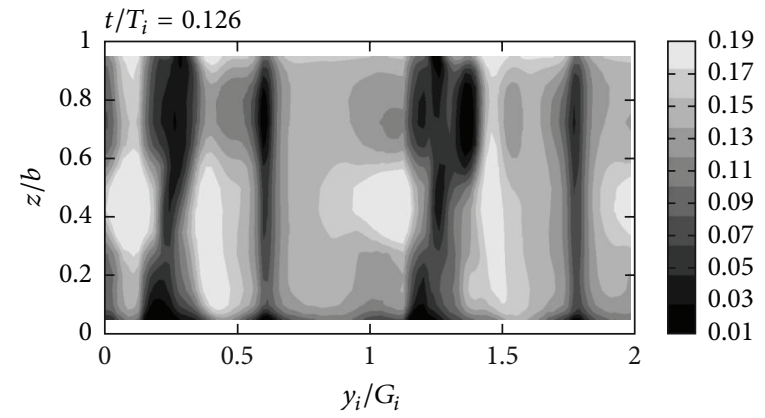

(d) Unsteady realizable $k-\varepsilon$

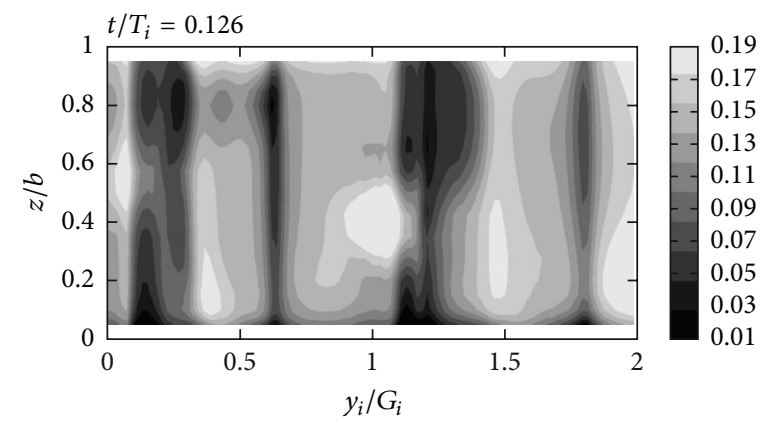

(e) Unsteady $k-\omega$ SST

FIgURE 17: Radial velocities in the radial gap $\left(R / R_{2}=1.02\right)$.

Q: $\quad$ Flow rate $\left(\mathrm{m}^{3} / \mathrm{s}\right)$

$\varphi$ : Flow rate coefficient, $4 Q /\left(U_{2} \pi D_{2}^{2}\right)$

$\Psi$ : Total pressure rise coefficient, $2\left(p_{\text {out }}-p_{\text {in }}\right) / \rho U_{2}^{2}$

$\widetilde{C}_{p}: \quad$ Static pressure coefficient, $2\left(p-p_{\text {in }}\right) / \rho U_{2}^{2}$

$p_{\text {in }}$ : Static pressure at the inlet of pump $(\mathrm{Pa})$

$p_{\text {out }}$ : Static pressure at the outlet of the pump $(\mathrm{Pa})$

$n$ : Rotational speed (rpm)

Re: Reynolds number, $U_{2} l / v$

$v$ : Kinematic viscosity $\left(\mathrm{m}^{2} / \mathrm{s}\right)$

$l$ : Impeller chord length $(\mathrm{m})$

$G_{i}: \quad$ Circumferential pitch, $2 \pi / z_{i}$

$T_{i}$ : $\quad$ Rotor blade passing period, $2 \pi / n z_{i}$

$y_{i}$ : Circumferential coordinate in the relative frame

$W_{r}:$ Radial velocity $(\mathrm{m} / \mathrm{s})$

$W_{u}$ : Tangential velocity $(\mathrm{m} / \mathrm{s})$ $\rho:$ Fluid density $\left(\mathrm{kg} / \mathrm{m}^{3}\right)$

$f_{r}$ : Frequency of the rotor $(\mathrm{Hz})$

$f_{i}$ : Frequency of the impeller blade $(\mathrm{Hz})$

$f_{d}$ : Frequency of the diffuser vane $(\mathrm{Hz})$.

\section{Acknowledgments}

The authors would like to express their greatest thanks to Professor Marina Ubaldi who made the experimental results of the ERCOFTAC centrifugal pump available. The research presented was carried out as a part of the "Swedish Hydropower Centre-SVC" (http://www.svc.nu/). SVC was established by the Swedish Energy Agency, Elforsk and Svenska Kraftnät together with Luleå University of Technology, The Royal Institute of Technology, Chalmers University of Technology, and Uppsala University. The computations were 
made using resources provided by the Swedish National Infrastructure for Computing (SNIC) at $\mathrm{C}^{3} \mathrm{SE}$ and Lunarc.

\section{References}

[1] R. P. Dring, H. D. Joslyn, L. W. Hardin, and J. H. Wagner, "Turbine rotor-stator interaction," ASME Journal of Engineering for Power, vol. 104, no. 4, pp. 729-742, 1982.

[2] N. Arndt, A. J. Acosta, C. E. Brennen, and T. K. Caughey, "Experimental investigation of rotor-stator interaction in a centrifugal pump with several vaned diffusers," ASME Transactions, vol. 112, no. 1, pp. 98-108, 1990.

[3] M. Ubaldi, P. Zunino, G. Barigozzi, and A. Cattanei, "An experimental investigation of stator induced unsteadiness on centrifugal impeller outflow," Journal of Turbomachinery, vol. 118, no. 1, pp. 41-51, 1996.

[4] M. Ubaldi, P. Zunino, G. Barigozzi,, and A. Ghiglione, "Nonintrusive measurements of the unsteady flow in the radial gap between centrigugal impeller and vaned diffuser," in Proceedings of the 12th Symposium on Measuring Techniques for Transonic and Supersonic Flow in Cascades and Turbomachines, University of Cambridge, Cambridge, UK, 1994.

[5] M. Ubaldi, P. Zunino, G. Barigozzi, and A. Ghiglione, "LDV investigation of the rotor-stator aerodynamic interaction in a centrifugal turbomachine," in Proceedings of the 8th International Symposium on Applications of Laser Techniques to Fluid Mechanics, 1996.

[6] M. Ubaldi, P. Zunino, and A. Ghiglione, "Detailed flow measurements within the impeller and the vaneless diffuser of a centrifugal turbomachine," Experimental Thermal and Fluid Science, vol. 17, no. 1-2, pp. 147-155, 1998.

[7] H. Keck and M. Sick, "Thirty years of numerical flow simulation in hydraulic turbomachines," Acta Mechanica, vol. 201, no. 1-4, pp. 211-229, 2008.

[8] J. F. Combes, “Test case U3: centrifugal pump with a vaned diffuser," in Proceedings of the ERCOFTAC Seminar and Workshop on Turbomachinery Flow Prediction VII, 1999.

[9] P. F. Bert, M. Pessiani, J. F. Combes, and J. L. Kueny, "Unsteady flow calculation in a cross-flow fan using a finite element method," in Proceedings of the ASME International Gas Turbine and Aeroengine Congress \& Exhibition, 1996.

[10] M. Zhang, H. Wang, and H. Tsukamoto, "Numerical analysis of unsteady hydrodynamic forces on a diffuser pump impeller due to rotor-stator interaction," in Proceedings of the ASME Joint US-European Fluids Engineering Conference, 2002.

[11] K. Majidi, "Numerical study of unsteady flow in a centrifugal pump," Journal of Turbomachinery, vol. 127, no. 2, pp. 363-371, 2005.

[12] H. Nilsson, M. Page, M. Beaudoin, and H. Jasak, "The OpenFOAM turbomachinery working group, and conclusions from the turbomachinery session of the third OpenFOAM workshop," in Proceedings of the 3rd IAHR International Meeting of the Workgroup on Cavitation and Dynamic Problems in Hydraulic Machinery and Systems, Brno, Czech Republic, 2009.

[13] H.G. Weller, G. Tabor, H. Jasak, and C. Fureby, "A tensorial approach to computational continuum mechanics using objectoriented techniques," Computers in Physics, vol. 12, no. 6, 1998.

[14] O. Petit, H. Nilsson, T. Vu, O. Manole, and S. Leonsson, "The flow in the U9 Kaplan turbine-preliminary and planned simulations using CFX and OpenFOAM," in Proceedings of the 24th IAHR Symposium on Hydraulic Machinery and Systems, 2008.
[15] S. Muntean, H. Nilsson, and R. F. Susan-Resiga, “3D Numerical analysis of the unsteady turbulent swirling flow in a conical diffuser using fluent and OpenFOAM," in Proceedings of the $3 r d$ IAHR International Meeting of the Workgroup on Cavitation and Dynamic Problems in Hydraulic Machinery and Systems, Brno, Czech Republic, 2009.

[16] H. Nilsson, "Evaluation of OpenFOAM for CFD of turbulent flow in water turbines," in Proceedings of the 23rd IAHR Symposium on Hydraulic Machinery and Systems, 2006.

[17] O. Petit, M. Page, M. Beaudoin, and H. Nilsson, "The ERCOFTAC centrifugal pump OpenFOAM case-study," in Proceedings of the 3rd IAHR International Meeting of the Workgroup on Cavitation and Dynamic Problems in Hydraulic Machinery and Systems, Brno, Czech Republic, 2009.

[18] H. K. Versteeg and W. Malalasekera, Eds., An Introduction to Computational Fluid Dynamics: The Finite Volume Method, Pearson Education, 2nd edition, 2007.

[19] M. Beaudoin and H. Jasak, "Development of a generalized grid interface for turbomachinery simulationswith OpenFOAM," in Proceedings of the Open Source CFD International Conference, Berlin, Germany, 2008.

[20] A. Atif, S. Benmansour, G. Bois, and P. Dupont, "Numerical and experimental comparison of the vaned diffuser interaction inside the impeller velocity field of a centrifugal pump," Science China Technological Sciences, vol. 54, no. 2, pp. 286-294, 2011.

[21] O. Petit, A. I. Bosioc, H. Nilsson, S. Muntean, and R. F. SusanResiga, "Unsteady simulations of the flow in a swirl generator, using OpenFOAM," International Journal of Fluid Machinery and Systems, vol. 4, pp. 199-208, 2008.

[22] P. Moradnia, CFD of air flow in hydro power generators [Licentiate thesis], Division of Fluid Dynamics, Chalmers University of Technology, 2010.

[23] F. S. Lien and M. A. Leschziner, "Computational modeling of 3D turbulent flow in s-diffuser and transition ducts," in Proceedings of the 2nd International Symposium of Engineering Turbulence Modeling and Experiments, vol. 2, pp. 217-228, 1993.

[24] V. Yakhot, S. A. Orszag, S. Thangam, T. B. Gatski, and C. G. Speziale, "Development of turbulence models for shear flows by a double expansion technique," Physics of Fluids A, vol. 4, no. 7, pp. 1510-1520, 1992.

[25] T.-H. Shih, W. W. Liou, A. Shabbir, Z. Yang, and J. Zhu, "A new $\mathrm{k}-\varepsilon$ eddy viscosity model for high reynolds number turbulent flows," Computers and Fluids, vol. 24, no. 3, pp. 227-238, 1995.

[26] F. R. Menter, "Two-equation eddy-viscosity turbulence models for engineering applications," AIAA Journal, vol. 32, no. 8, pp. 1598-1605, 1994.

[27] J.-F. Combès, P.-F. Bert, and J.-L. Kueny, "Numerical investigation of the rotor-stator interaction in a centrifugal pump using a finite element method," in Proceedings of the ASME Fluids Engineering Division Summer Meeting (FEDSM '97), June 1997. 

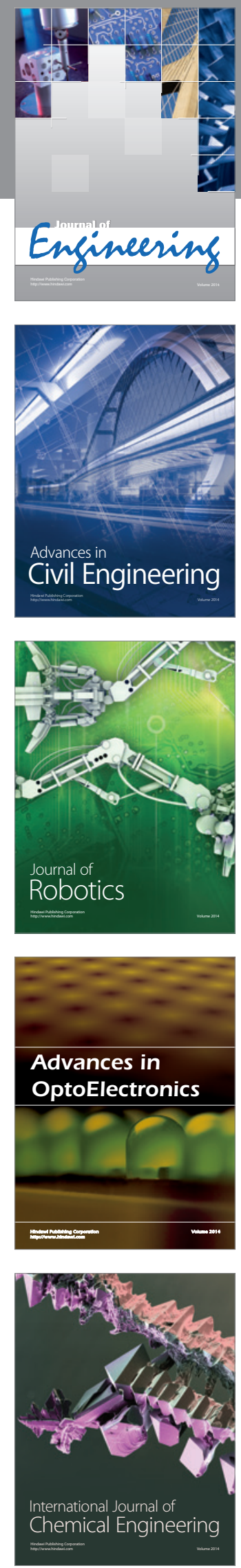

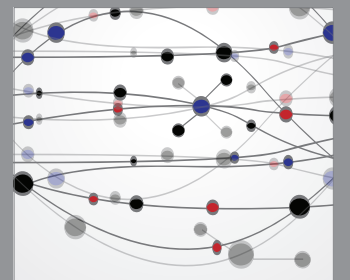

The Scientific World Journal
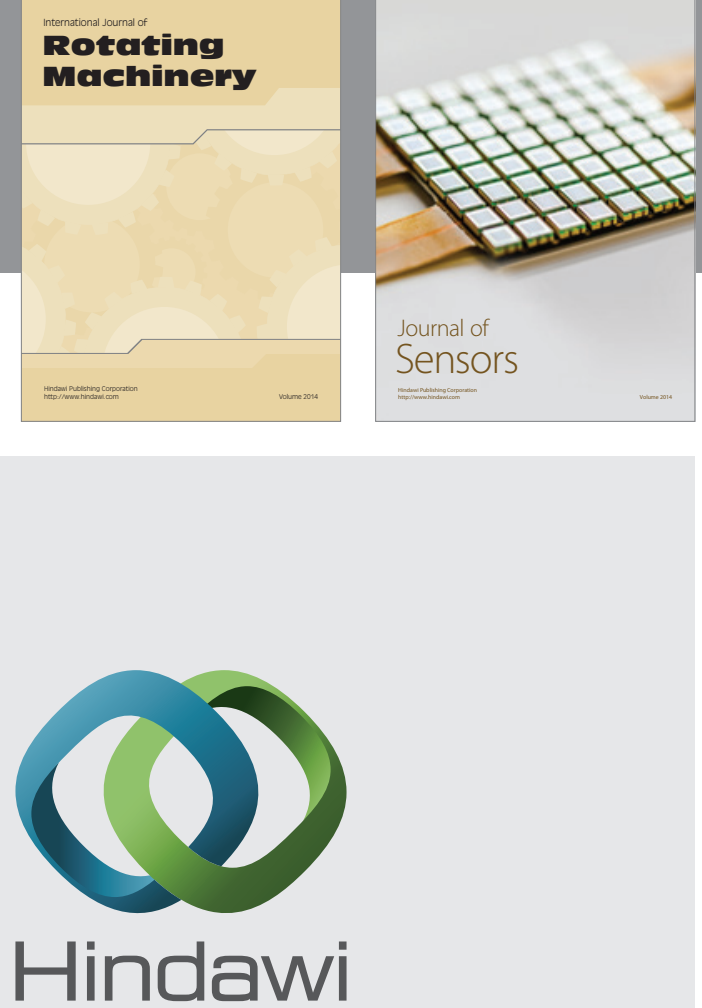

Submit your manuscripts at http://www.hindawi.com
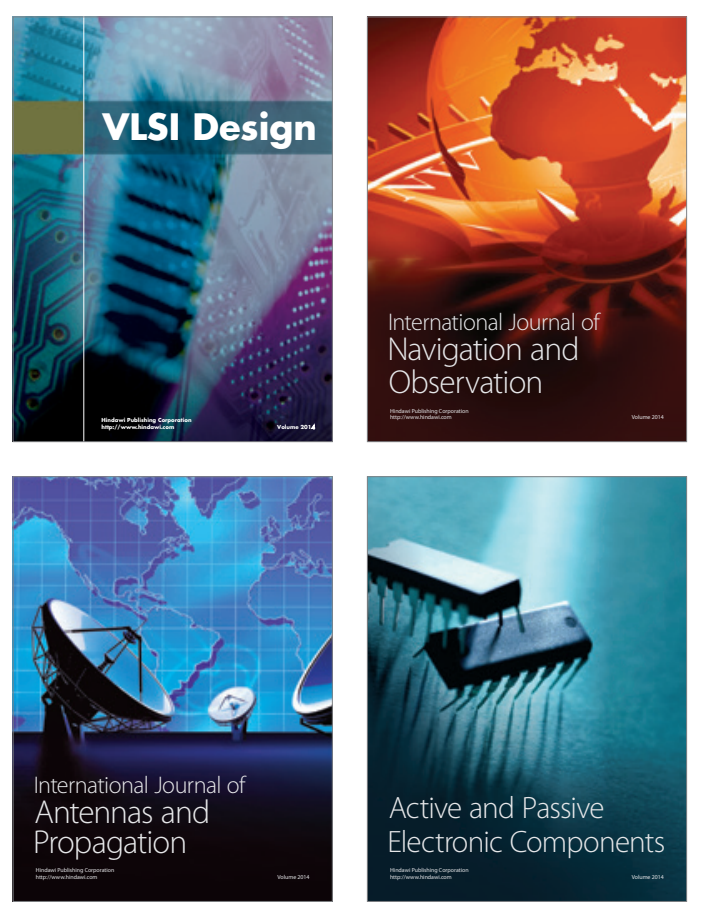
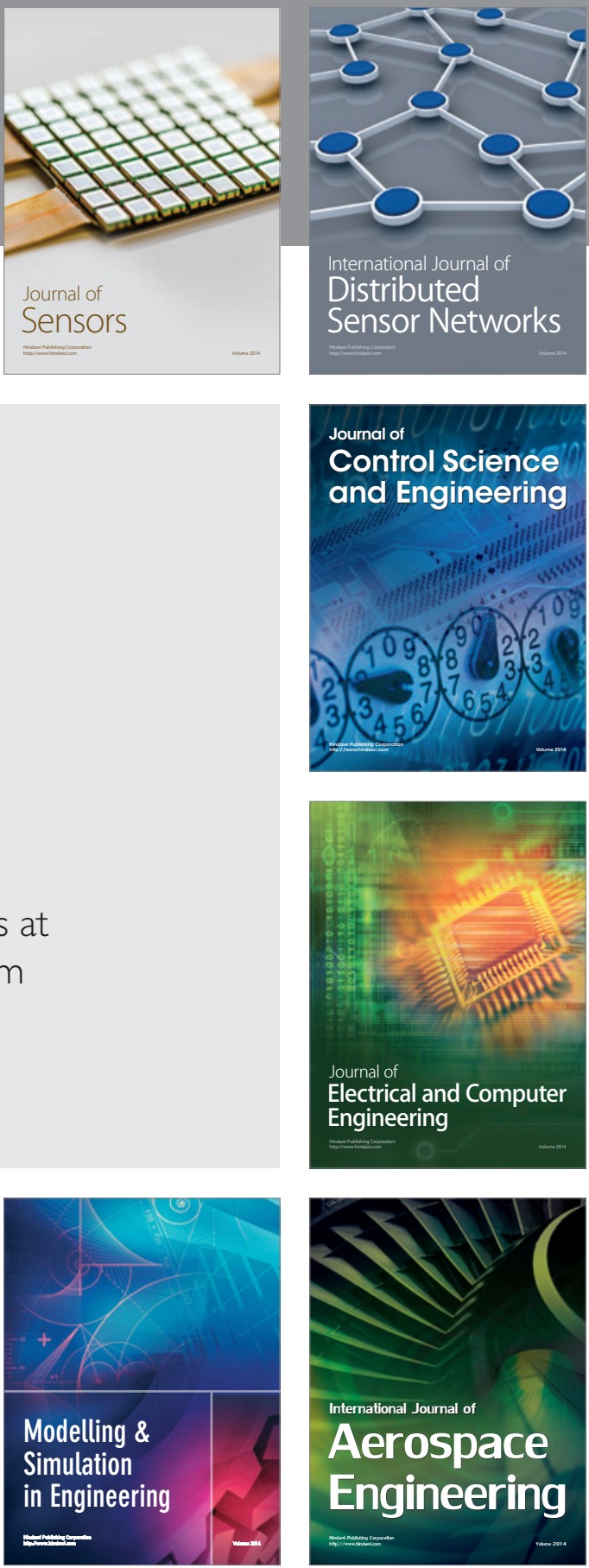

Journal of

Control Science

and Engineering
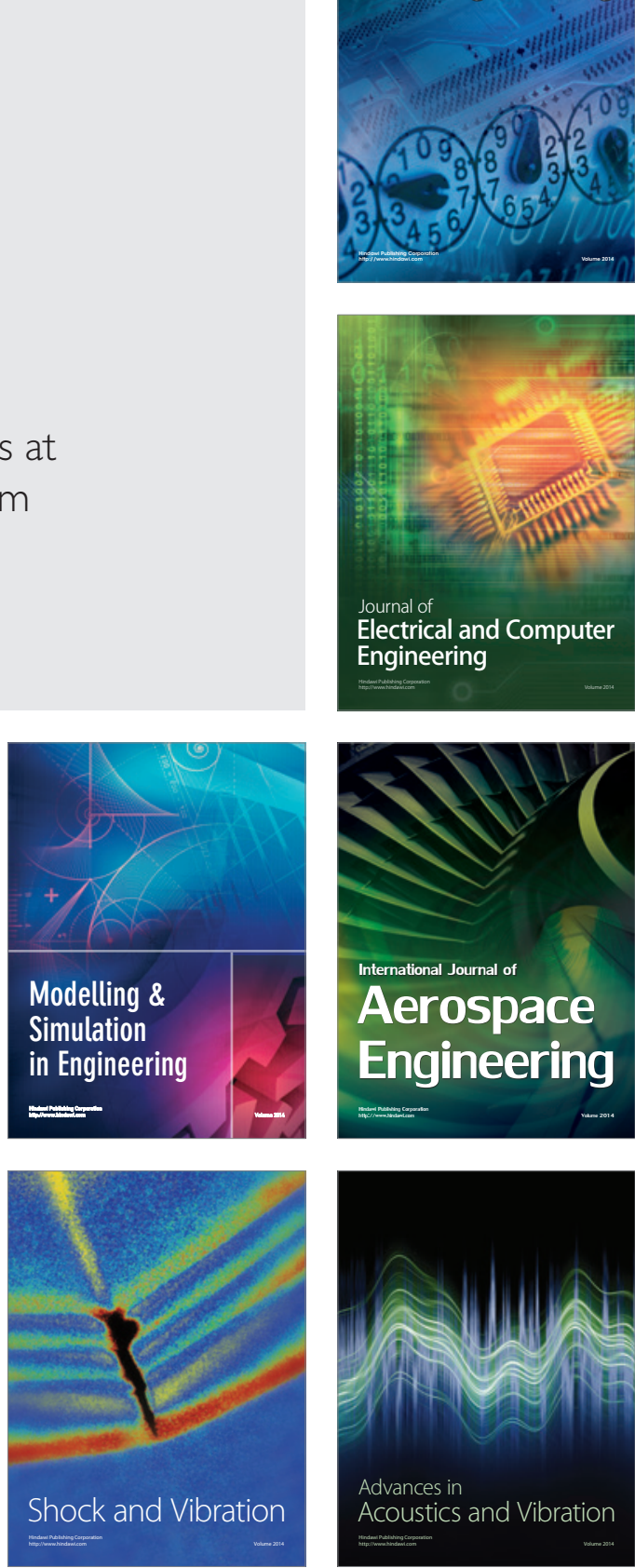